\title{
Seven solutions for neuroprotection in Parkinson's disease
}

\begin{tabular}{|c|c|}
\hline Journal: & Movement Disorders \\
\hline Manuscript ID & MDS-20-1261.R1 \\
\hline Wiley - Manuscript type: & Review \\
\hline $\begin{array}{r}\text { Date Submitted by the } \\
\text { Author: }\end{array}$ & $n / a$ \\
\hline Complete List of Authors: & $\begin{array}{l}\text { Devos, David; University of Lille Nord de France, Medical Pharmacology } \\
\text { Hirsch, Etienne; Institut du Cerveau et de la Moelle Épinière, INSERM } \\
\text { U1127, CNRS } 7225 \text { Experimental therapeutics of Parkinson disease; } \\
\text { Wyse, Richard; The Cure Parkinson's Trust }\end{array}$ \\
\hline Keywords: & $\begin{array}{l}\text { Parkinson's disease, drug development, preclinical studies, clinical trial, } \\
\text { neuroprotection, disease-modifying effect }\end{array}$ \\
\hline
\end{tabular}

\section{SCHOLARONE \\ Manuscripts}




\title{
Seven solutions for neuroprotection in Parkinson's disease
}

\author{
David Devos $\mathrm{MD}, \mathrm{PhD}^{(1)^{*}}$, Etienne Hirsch $\mathrm{PhD}^{(2)^{*}}$, Richard Wyse $\mathrm{PhD}^{(3)^{*}}$ \\ (1) University of Lille, Department of Medical Pharmacology, Expert center for \\ Parkinson, CHU-Lille, Lille Neuroscience \& Cognition, Inserm, UMR-S1172, \\ LICEND, NS-Park network, France \\ (2) Institut du Cerveau - ICM, Inserm U 1127, CNRS UMR 7225, Sorbonne Université, \\ F-75013, Paris, France \\ (3) The Cure Parkinson's Trust, London, UK \\ * Authors equally contributed
}

Corresponding authors: Devos David \& Etienne Hirsch

david.devos@chru-lille.fr ; etienne.hirsch@upmc.fr

ORCID numbers:

David Devos: 0000-0002-2417-799X

Etienne Hirsch: 0000-0003-4823-276X

Richard Wyse: 0000-0001-9542-5033X

Running title: Neuroprotection in Parkinson's disease

Keywords: Parkinson's disease - drug development - preclinical studies - clinical trial neuroprotection - disease-modifying effect.

Title: 58 characters including space, running title: 39 characters including space, Abstract: 160 words, text: 4799 words; Figure: 3; references: 92 


\begin{abstract}
Parkinson's disease (PD) is a neurodegenerative disorder characterized by loss of dopaminergic neurons in the substantia nigra, and accumulation of iron and alpha-synuclein; it follows a characteristic pattern throughout the nervous system. Despite, decades of successful preclinical neuroprotective studies, no drug has then shown efficacy in clinical trials. Considering this dilemma, we have reviewed and organized solutions of varying importance that can be exclusive or additive and outline approaches to help generate successful development of neuroprotective drugs for PD: 1) select patients in which the targeted mechanism is involved in the pathological process associated with the monitoring of target engagement; 2) combine treatments that target multiple pathways; 3) establish earliest interventions and develop better prodromal biomarkers; 4) adopt rigorous methodology and specific disease-relevant designs for disease-modifying clinical trials; 5) customize drug with better brain biodistribution; 6) prioritize repurposed drugs as a first line approach; 7) adapt preclinical models to the targeted mechanisms with translational biomarkers to increase their predictive value.
\end{abstract}




\section{Introduction}

Parkinson's disease (PD) is a complex neuropsychiatric disorder. ${ }^{1,2}$ It is a progressive and topographically extensive neurodegenerative disease, with a classical pathological hallmark that involves dopaminergic neuron regulated cell death, notably in the substantia nigra pars compacta (SNpc). It is associated with iron accumulation, oxidative stress, nitrosative stress, lipid peroxidation, neuro-inflammation, glutamate excitotoxicity, mitochondrial deficits, lysosome and proteasome alteration with protein misfolding notably of alpha synuclein ( $\alpha$-syn) with aggregates. ${ }^{3-5}$

Many preclinical studies have identified efficient therapeutic strategies that work well in animal models of PD, but so far, none of them has been confirmed to be effective in clinical trials in patients (Figure 1). Consequently, many pharmaceutical and biotechnology companies have been reluctant to enter or even remain in the field of PD drug development. One conceivable fundamental problem for the repetitive failure to convert positive pre-clinical results into therapeutic success might be that PD does not consist of a single disorder, but rather, it consists of a syndrome that shares only weak biologic commonalities and thus requires a careful molecular and clinical triage. ${ }^{6}$

Another major difficulty in developing clinical trials for neuroprotection is the fact that the brain is not accessible for in vivo neuronal counts, and therefore there are no tools in the clinic capable of monitoring neuroprotection. Consequently, the term "disease modifier" was introduced in the field (Figure 2). The concept of a disease modifying agent implies that it is able to demonstrate a tangible impact on molecular mechanisms known to be involved in the degenerative process. Currently, many of these cannot be fully demonstrated in patients due to limitations in brain accessibility, and the lack of suitable biochemical imaging markers. In this review, we identify and discuss seven current limiting factors of neuroprotective strategies and propose solutions for each of these to help develop efficient treatments aiming at reducing the rate of downward trajectory of disease progression in PD (Figure 3). Importantly, these solutions are not of equal importance, some of them being exclusive and others additive.

\section{Search strategy and selection criteria}

To the best of our knowledge, there is no review describing the strategies required for a translational development of a treatment for neuroprotection in PD. References for this review 
were identified by searches of PubMed between 1969 and July 2020. The search terms were guided by two strategies: 1) recent reviews on each topic and 2) examples to illustrate the concepts and the solutions.

\section{Challenge 1: PD is not just "heterogeneous" or "complex" but a syndrome.}

PD belongs to the wide range of complex multifactorial and polygenic disorders influenced both by genetic and environmental factors, and is very likely a combination of both in a large proportion of PD patients. Less than $10 \%$ of PD cases have a monogenic origin. The known causal mutations affect 15 genes and explain only about $30 \%$ of monogenic (and 3-5\% of sporadic) cases. ${ }^{6}$ Moreover, the monogenic forms display a variable penetrance, variable expression and a very long pre-symptomatic phase, suggesting that other causal and risk factors are involved in the pathogenesis. Unbiased genome-wide association studies (GWAS) have demonstrated a role of more common genetic variants, leading to the concept of 'graded risk', which is a continuum from Mendelian mutations, low frequency disease-causing mutations, and common polymorphisms with an associated strong-to-low impact on the disease expression and progression. ${ }^{7-11}$ A similar level of complexity of provenance applies to our understanding of the environmental toxic causes of PD. ${ }^{12}$ Exposure to pesticides have been reported to increase the risk of developing PD, especially for farmers employing organo-chloride chemicals, ${ }^{13-15}$ exposure to MPTP 16 , and intoxication by n-hexane, ${ }^{17}$ atypical French Caribbean Parkinsonism. ${ }^{18}$ Noteworthy, most of these environmental compounds are inhibitors of mitochondrial complex 1, which suggests this as a specific pathway of neurodegeneration. This complicated situation might be made even more complex due to the behavioral consumption of substances during one's lifetime that might themselves also alter PD progression. Indeed, the risk of developing PD has been shown to be lower in smokers than in non-smokers, ${ }^{19,20}$, or in individuals treated by anti-inflammatory drugs such as Ibuprofen. ${ }^{21}$ Consequently, it is important to consider the various etiologies and risk factors of PD on one hand whilst, on the other hand, also actively consider the positive and negative risk factors that influence the rate of disease progression. A major limitation of most neuroprotective PD clinical trials is that the precise etiology of the disease, and the prior individual environmental exposures of the patients recruited into these studies, remains unknown.

\section{Solution 1: To develop clinical trials on patients with known etiology and risk factors}

In a diabetic patient, no one would prescribe anti-diabetic drugs without considering the patient's dependency on taking insulin. However, it is exactly this type of mistake we are 
making in the field of PD by including patients with mixed etiologies in neuroprotection trials. There is now a clear need for changing the strategy and performing clinical trials on wellcharacterized populations of patients. Despite the small number of patients with a genetic origin of their disease, clinical trials should be developed on populations of patients with identical mutations. Furthermore, the diagnosis of PD should be validated by combining specific clinical criteria (MDS) 22,23 and imaging of dopamine depletion for inclusion criteria of de novo patients. ${ }^{24,25}$ This is especially important in carriers of PD causative mutations, as they might still be in a presymptomatic stage of the disease. Furthermore, because in patients with identical mutations the clinical and pathological expression of the disease might vary, ${ }^{7,9}$ selecting more homogenous subpopulations according to the rate of progression of the disease and prognosis factors should be the gold standard. Indeed, in de novo patients, probable predictors of more rapid motor decline and disability could be used - such as higher age at onset, baseline motor impairment with higher postural instability, and gait disorders score (non-tremor dominant subtype), cognitive impairment and depression. ${ }^{26,27}$ However, specific criteria validated with a rigorous approach on large cohorts are still lacking. ${ }^{28}$

Even patients with exactly the same mutation can display different phenotypes. This is very likely due to different environmental exposures during life, as well as incomplete penetrance. Thus, the concept of 'graded risk' developed from genetic research needs to associate the environment causes and risk factors. The genetic approaches that identify very rare causative mutations underlying monogenic forms and common variants with small effects need to be associated with questionnaires and biological samples for environmental factors, ${ }^{12-19}$ the comorbidities, and the antiparkinsonian and other treatments. By comparing large cohorts of patients and controls, machine learning and deep learning might allow stratifying the various subpopulations according to the risk factors of developing PD with omics and epigenetic analyses to develop the future biomarkers of patient stratification for upcoming trials. ${ }^{8}$ The same strategy needs to be developed on longitudinal cohorts of patients with respect to the accurate selection of trial end points of disease progression, or time to chosen milestones, or the novel weighted composite endpoint (PDCORE) ${ }^{29}$.

Altogether, a better characterization of the patients in terms of the causes and the factors of their disease progression will lead to a better stratification and to reduce patient variability in order to improve the statistical accuracy of the outcomes and end-points measured (Figure 3).

\section{Challenge 2: Targeting single pharmacological pathways is not efficient}


The mechanisms leading to neurodegeneration in PD include multiple pathways. ${ }^{3-5}$ Ultimately, neurons die by regulated cell death. However, 14 separate types of cell death have now been defined. ${ }^{55}$ Apoptosis, ferroptosis, necroptosis, autophagy and parthanatosis (target of rapamycin (mTOR) poly (ADP-ribose) (PAR) polymerase-1 (PARP-1)) appear to be particularly relevant for PD. ${ }^{56-59}$ Yet, further studies are required to better characterize the exact types of cell death that are most relevant in PD neurodegeneration. Importantly, recent research in cancer has demonstrated that, while there are distinct individual forms of cell death involved, they also display key connections between them, notably between ferroptosis, autophagy and parthanatosis. ${ }^{60,61}$ In addition, whether these molecular and cellular interactions represent a cause or a consequence of neurodegeneration in PD still needs clarification. An important issue for developing efficient neuroprotective trials is to determine whether the molecular changes involved actually belong to the same molecular pathways or instead to parallel pathways (i.e. different pathways). Of course, a broad action on several pathways will largely increase the chance of success.

\section{Solution 2: Identify all PD-relevant pathways of cell death and combine treatments that target multiple pathways}

Identifying the interactions between the molecular and cellular changes seen in PD is a key requirement in terms of informing how best to establish robust neuroprotection. Of course, if they belong to the same pathway blocking the deleterious mechanism, whether upstream or downstream to these molecular targets, this will result in the same protective effect and a single drug might therefore likely be highly efficient. On the other hand, if they belong to parallel pathways, then blocking one of these will not result in neuroprotection since the deleterious effects of the other pathway will still contribute to the neurodegenerative process. It has been exemplified in experimental models of PD that mitochondrial complex 1 deficiency and proteasome dysfunction belong to parallel pathways. ${ }^{62}$ Thus, if this is similarly true in human pathology, then disease-modifying clinical trials will require a combination of two or more drugs, and thereby targeting multiple pathways involved in neurodegeneration. Alternately, one might consider using drugs with a pleiotropic action, or using an appropriate combination of drugs. Yet, drug agencies still require proof of efficacy of each single drug - as monotherapies - before approving the development of any combinations of these drugs. But such a multi-drug strategy has already been proven to be highly successful in the fields of cancer, HIV and tuberculosis. Future neuroprotective strategies in PD should similarly test combinations of drugs selected on the basis of the various relevant mechanisms of cell death in any given 
subtype of PD. This strategy has recently started in amyotrophic lateral sclerosis with a combination of two drugs already in use (sodium phenylbutyrate and tauroursodeoxycholic acid). ${ }^{63}$ However, this strategy will not overcome the problem of whether any of the pathways targeted are truly at play in the population recruited for those trials.

\section{Challenge 3: Neuroprotective interventions are initiated too late in the course of the disease}

Most clinical trials are started a few years after the onset of symptoms, partly to ensure all enrolled patients have a reliable diagnosis of PD. Yet, imaging studies of dopaminergic markers have estimated there is a preclinical period of 15 to 20 years in younger, and 10 years in older, PD patients. ${ }^{30}$ By the time motor symptoms appear, patients have, lost 80 percent of their striatal dopamine, corresponding to $50 \%$ loss of dopaminergic neurons in the substantia nigra. ${ }^{31,32}$ Additionally, neuropathological examinations have, years before the SNpc is affected, shown lesions in the olfactory bulb, mesenteric plexus, brainstem including locus coeruleus, and raphe nucleus. ${ }^{16,33}$ Finally, the neurodegenerative process might by itself engage a self-perpetuating phenomenon as shown in the human subjects intoxicated by MPTP. Thus, it is clear that late therapeutic intervention obviously decreases the chance of success.

\section{Solution 3: To establish early interventions and develop better prodromal biomarkers}

The prodromal phase is theoretically the best period to start any neuroprotective treatment, and it should ideally be initiated before any important damage of the nigro-striatal pathway has occurred corresponding to the first stages ( 1 and 2) of Braak's classification. ${ }^{33}$ However, there are two major limitations. i) The spectrum of symptoms during these early Braak's stages remains complex and very variable among patients. ${ }^{34,35}$ ii) Some individuals recruited during the prodromal phase may not express the disease, or may only develop it very late. This calls for a search of better diagnosis biomarkers (wet, dry, wearable) during the prodromal phase of the disease, and incorporating likelihood ratios with age and gender (of developing overt PD), and improved predictive algorithms generated by big data approaches to predict the likelihood of progression into the symptomatic phase. ${ }^{35-38}$

Until now de novo patients have constituted the best population for neuroprotective trials, with the aim that the remaining dopaminergic neurons can be saved. ${ }^{39-42}$ Furthermore, at this stage, there is no interference of dopaminergic treatment on the analysis of any neuroprotective effect. However, it is difficult to recruit de novo patients for several reasons. 1) There is a risk of 
including atypical forms and lack of dopamine depletion. 2) There is a higher patient dropout rate because patients are stressed, or in denial, after receiving their diagnosis, and may poorly tolerate the lack of symptomatic treatment. ${ }^{42-45}$ Another alternative is to perform the trials on early PD patients (within the first 3 years after diagnosis) because they receive a stable, moderate-dose regimen of dopaminergic drugs and could still benefit from an intervention that would reduce the rate of disease progression. Furthermore, these patients are easy to recruit and allow studying the interactions between the neuroprotective compound and dopamine agonists and/or L-dopa. ${ }^{42-45}$

The ideal population of patients to include in neuroprotective trials are those characterized by a genetic trait, or by a biomarker that would confirm the diagnosis during the presymptomatic phase and that can demonstrate the molecular susceptibility to the mechanism of the drug to which it is exposed. Asymptomatic carriers of mutations causative of PD represent the best population to study. Yet, in such patients, the onset of the symptoms is very difficult to predict. One strategy would consist of performing neuroprotective trials in these patients a few years before the mean age of onset in such a specific population. The read-out of these types of neuroprotective studies would then be the "delayed time to transition" to the symptomatic phase. Yet, such patients are relatively rare and inclusion difficulties might prevent extensive clinical trials unless run as a global effort. Furthermore, because of the variability in the duration of the asymptomatic phase due to variable penetrance of the genes involved, such initiatives might also require long study durations, thereby increasing their cost. ${ }^{6,42-45}$

Because of the difficulties in performing clinical trials in inherited forms of PD, neuroprotective approaches should also be tested in sporadic cases. To do this, there is a need for diagnostic biomarkers during the prodromal phase of the disease. Many studies have attempted to identify such wet and dry biomarkers. $6,38,40,42,43,45-48$ Among those candidates, $\alpha$-synuclein ( $\alpha$-syn) is regarded by many as the most promising. ${ }^{6,33,41}$ However, PD is usually associated with abnormal accumulation of several other types of misfolded proteins, notably $\beta$-amyloid and tau, which co-occur with $\alpha$-syn. 6,33,41 Moreover, Lewy pathology is not necessarily found in all forms of PD (e.g. some leucine-rich repeat kinase 2 (LRRK2) patients, and most of the Parkinrelated cases). ${ }^{6,48}$ Furthermore, even in cases with clear synucleinopathies, there is no dosedependent correlation between Lewy pathology, cell loss and clinical features. ${ }^{49,50}$ Consequently, $\alpha$-syn represents a convenient pathologic biomarker but may not be pathogenic with the exception of $\alpha$-syn-related genetic PD patient subtypes. ${ }^{51-54}$ Moreover, $\alpha$-syn 
determination in fluids or peripheral tissues cannot be the sole surrogate biomarker of PD because its concentration is modified by complex physiopathological responses within the body, as well as being modified by the consequences of PD neurodegeneration. Further studies are required to analyze the dynamic expression and deposition of $\alpha$-syn during PD disease progression, ideally using a translational approach.

\section{Challenge 4: The methodology of clinical trials is not adapted to progressive long-term neurodegeneration}

The design of disease-modifying, neuroprotective clinical trials in PD patients is very challenging for several reasons. First, there is no reference drug, nor any clinical trial design, that has ever shown efficiency for neuroprotection. This might be due to the lack of efficacy of the tested drugs and/or from poor clinical trial designs, or both. This problem is even more complex in PD because the tested medications might have both a symptomatic and a neuroprotective effect. Second, biomarkers of neuroprotection are still lacking and it is therefore difficult to determine on rational scientific grounds whether or not the drug being tested is actually reaching its biological target and is thereby having a positive effect at a cellular level. Thus, clinical trials mostly rely on clinical outcomes. However, the clinical symptoms are, themselves, not very sensitive to be able to demonstrate meaningful change since they do not progress rapidly enough to measure accurately, at least not over the study durations, typically 1 year, chosen for most neuroprotective clinical trials in PD patients. Third, even with well-validated scales such as UPDRS, drug testing of putative neuroprotective agents is not typically performed in a real-life environment. Finally, the global handicap (i.e. motor, cognitive and behavior), also including the rather more variable non-motor symptoms, needs to be considered. All of this, calls for new designs of neuroprotection trials in PD.

\section{Solution 4: To adopt rigorous methodology and specific disease-relevant designs for PD neuroprotective clinical trials}

It is clear that greater attention must be paid in selecting the most appropriate clinical trial design, with either an adaptation of a well-tested design, or new approach depending on any suspected possibility or likelihood that the neuroprotective drug under investigation may also have a concomitant symptomatic effect.6,42-45 (Figure 3) Adaptive trials have been also proposed as a version of the responder trial..$^{71}$ A first discovery phase includes a broad population with several subtypes followed by a validation phase considering only the best patient responders. Master protocols, including "basket trials", "umbrella trials", and "platform 
trials", use a trial network with shared infrastructure and are designed with multiple sub-studies to evaluate one or more investigational drugs in one or more disease subtypes. ${ }^{72,73}$ Following the same idea, multi-arm, multi-stage (MAMS) trials have been recently proposed to test many potential therapies currently in the pipeline in parallel (multi-arm), transitioning seamlessly through various phases (multi-stage), i.e., from a phase II safety and efficacy study to a phase III trial, with the help of a platform. ${ }^{74}$ While they are attractive, they come from the oncology field where the simultaneous therapeutic use of multiple drugs is already validated and accepted by regulatory authorities, which is far from the current case for PD.

The demonstration of the reduction of an already slow disease progression is very challenging since it requires a long-term study during which the symptomatic dopaminergic requirements of patients are frequently changing, and this can greatly confuse the interpretation of neuroprotective results. Regarding the duration of the trial, if a symptomatic treatment is not introduced or modified, a period between 6 to 12 months represents a reasonable and practical compromise between having sufficient time to observe a neuroprotective effect and the relatively limited number of patient dropouts set against an attrition of study subjects that inevitably continues to increase over longer trial durations. For example, a study duration of 6 months in de novo patients was associated with a drop-out rate of $10-15 \%$ in the ADAGIO trial. ${ }^{75}$ Conversely, a 9-month period would have a greater chance of clinical success but at the expense of a higher drop-out rate in de novo patients. ${ }^{45}$

The current MDS-UPDRS clinical scales are not designed to assess subtle modifications of disease progression. This low sensitivity to monitor change requires a very large population of patients to be followed for long periods of time, and this is very challenging for Phase II trial purposes. Using a biomarker as a primary outcome measure is an interesting alternative for an early phase II study. Objective and continuous measures offer a different perspective, with wearable technologies provide specific and rigorous quantification that could become efficient biomarkers of motor handicap in real life spanning over several days, such as, connected actimetry ${ }^{76}$ and connected soles for a continuous recording of gait and balance.

\section{Challenge 5: Targeting the central nervous system (CNS) represents a pharmacological challenge}

Another major challenge relates to the poor blood-brain-barrier (BBB) penetration of many candidate neuroprotective drugs. The competitive and variable drug penetration in the brain parenchyma leads to low and unpredictable bio-distribution in the CNS with additional 
confounding interference from dietary foods and drug interactions etc. Furthermore, for most of the drugs there is no measurement of its concentration in the brain parenchyma, nor of its engagement with its biological target in neurons. Thus, clinicians currently only rely on clinical scales or, in the best cases, also on various available imaging parameters of the brain.

The issue of BBB drug penetration might also be challenging due to blood vessel modifications associated with the disease process or the medication 77,78

\section{Solution 5: To customize drug with better and more selective brain accessibility}

Pharmacokinetic studies with drug concentration measurements should be associated in both preclinical and clinical studies. Yet, this is complex because cerebrospinal fluid (CSF) is not accessible on a repetitive basis and only gives a biased measurement of the drug concentration in the brain region targeted by the drug. Furthermore, sampling of both CSF and blood as a function of time after administration provides an estimate the precision of which will depend on the number of samples over time. The association of brain tissue and clinical measures respectively in both the experimental models and the patients - should ideally allow the establishment of an algorithm to help select the best dose and regimen in humans.

Another need is to improve drug penetration into the brain by customizing drugs with better penetration characteristics, or by developing prodrugs that will easily cross the BBB. Indeed, oral administration is obviously the easiest, but not the best, method of drug delivery for brain diseases. Transnasal delivery is also noninvasive and easy to operate and should be considered for intermittent administration of small molecules or small volumes of drug. ${ }^{79}$ Only small and lipophilic drugs can readily penetrate into the brain. In the situation where a very effective neuroprotective drug poorly penetrates the BBB, then several options might be usefully considered to help improve its brain penetration. The first option for small molecules is to increase their lipidation, or to reduce their size, keeping only the active neuroprotective fragment. Another interesting option is to use a lipophilic prodrug. ${ }^{80,81}$ Nanoparticles represent another chemical modification to increase BBB permeability (Figure 3). ${ }^{82,83}$

If, despite chemical modification, the drug does not penetrate into the brain parenchyma then instead, direct delivery in the brain might be considered. ${ }^{84}$ The procedure involving intrathecal administration of baclofen or painkillers has been reported to be effective, reversible, and safe in thousands of patients. ${ }^{85}$ The safety of brain infusion of growth factors has also generated promising results despite a lack of efficacy for neuroprotection. ${ }^{86} \mathrm{With}$ such procedures, high 
local drug and personalized concentrations can be achieved with no or minimal systemic adverse events.

Developments using physical, chemical and biological methods to open the BBB have also emerged recently. For example, focused ultrasound (FUS) has been shown to be safe and very efficient. Such approaches represent an interesting alternative for intermittent administration of drugs with long lasting effects. ${ }^{87,88}$ Co-administration of or substances acting on the efflux carriers, and transporters, can also theoretically increase drug penetration. ${ }^{84}$

\section{Challenge 6: Neuroprotection represents a very long and risky drug development}

Developing a new drug is always very long (an average of 14.2 years), very expensive (US $\$ 802$ million) and challenging. ${ }^{89}$

\section{Solution 6: To reduce the risk of drug development for PD}

Additional safeguards need to be developed with combined efforts both from academic partners and the drug industry. Prioritizing the development of repurposed drugs represents an attractive approach for neuroprotection in PD. Drugs already on the market for other therapeutic indications have the advantage of being already used for humans, and helpfully already have a well-known safety profile. Because of the extensive experience with these compounds they are generally also straightforward to test in preclinical models. Generally, their pharmacokinetic and pharmacodynamic characteristics are known, but the issues of brain penetration and adaptation of the dosage to the CNS might not be trivial. In terms of intellectual property, a new patent of an old drug for a new indication or formulae typically allows increasing the time for development for use in another indication. Target validation and lead molecule optimization can then be developed based upon this safe, first-in-class, repurposed drug.

Another way of reducing the risk for drug development in neuroprotection is based on the fact that a few drugs may have shown efficacy in animals, and then also shown encouraging results in humans, but were subsequently abandoned because of their toxicity in a very small number of patients. Yet, even if a drug does not have an ideal safety profile, rigorous monitoring can allow testing it in clinical trials. Deferiprone is currently being clinically assessed for conservative iron chelation despite a rare risk of agranulocytosis $(<0.8 \%) .{ }^{90,91}$

\section{Challenge 7: Animal models of PD are not predictive of clinical efficacy}


No molecule that has demonstrated positive in vitro, and in vivo, effects on neuroprotection has displayed any neuroprotective effect in clinical trials. ${ }^{42,64}$

\section{Solution 7: To adapt preclinical models of PD and research design to the clinical situation}

One of the reasons for the lack of predictive value of any of the PD animal models is the fact that these models cannot recapitulate the clinical situation. Animal models can inform about mechanisms of therapy but not about patient selection for that therapy. This is why one should associate, in a translational manner, dry and wet biomarkers of the targeted mechanisms both in the models, and in humans, to ascertain neuroprotection.

The prediction of neuroprotection requires human, non-oncogenic, cell models including LUHMES, primary dopaminergic neuron culture, patient-derived Inducible Pluripotent Stem cells and three-dimensional brain organoids ${ }^{65}$.

Several in vivo models have been generated through neurotoxin-based or genetic-based approaches in rodents, or non-human primates, to demonstrate and validate neuroprotection. Neurotoxin-induced models reproduce some of the key molecular alterations such as complex 1 deficiency, or proteasomal dysfunction. Chemicals such as 6-hydroxydopamine, MPTP, rotenone, annonacine, and paraquat are mainly used to generate these types of PD models. Protein accumulation can be generated via overexpression of $\alpha$-syn. In addition, protein aggregation pathology can be triggered by inoculating preformed fibrils of $\alpha$-syn in the brain. ${ }^{66}$ Yet, a limitation of these models is that not all of the molecular changes seen in PD actually coexist in a single model. It may be useful, to increase the prediction by associating different experimentations in different in vivo models (toxin and genetic hits), to reproduce far better the full pathological process as typically seen in PD. ${ }^{66}$

Another important issue of neuroprotection trials is that, even for a same mutation, the clinical phenotypes of the patients recruited into a trial do vary considerably. Preclinical neuroprotection studies should therefore be performed using animals of mixed genetic backgrounds, and not on inbreed animals from an identical genetic provenance, but this may necessitate an increase in the required number of animals to achieve statistical significance. 
The immune status of animals is also important to monitor because neuroinflammatory processes also participate to neuronal degeneration. Indeed, most preclinical studies are performed on animals housed in a sterile environment, but PD patients in their daily lives are in constant contact with multiple immune stimulating agents. Lipopolysaccharide, a bacterial membrane molecule well known for its immune stimulating properties, increases the sensibility to parkinsonian toxins in rodents. ${ }^{67}$ Such a phenomenon might even start very early during life as offspring of pregnant rats injected with LPS are also more sensitive to parkinsonian toxins. ${ }^{67}$ One should thus consider monitoring carefully the immune status of the animals or perhaps even house the animals in standard non-SFP facilities.

Because PD is in most cases associated with aging, preclinical studies should include old animals. Indeed, elderly humans, and old animals, show less neuronal plasticity ${ }^{68}$ a lower level of dopamine metabolism ${ }^{69}$ and a higher iron content (which increases the pro-oxidant status ${ }^{70}$ ), and they also display considerably different dose-related effects to drugs given. PD is more prevalent in men, but both genders need to be accurately assessed because huge differences between them can be observed in terms of dose effects and neuronal degeneration.

The chronicity (months or even years) both of the degenerative process, and of the treatment regimen given, as well as the time at which the treatment is first introduced (ideally at time of the onset of symptoms) should be accurately reproduced in animal models.

Finally, good practice standards should be used in preclinical studies just as is the case in the clinical studies (Figure 3). Such standards are costly and will dramatically reduce the number of studies but will undoubtedly increase their predictability.

\section{Conclusion}

We have described a number of critical hurdles that are currently hampering progress towards bringing effective neuroprotective therapeutic approaches to slow disease progression in patients with Parkinson's disease, which arguably represents the greatest unmet need in this therapeutic area. We do not believe any of these hurdles are intractable and, especially considering the wealth of promising new neuroprotective approaches that are currently emerging, we have therefore outlined and organized exclusive or additive solutions of varying importance to help generate successful development of neuroprotective drugs for PD solutions and approaches to help overcome most or all of these hurdles. 


\section{Financial Disclosures of all authors (for the preceding 12 months)}

$\mathrm{DD}, \mathrm{EH}, \mathrm{RW}$ have no conflict of interest regarding the review.

DD served on several Scientific Advisory Boards for Orkyn, Air Liquide, Lundbeck, Ever Pharma and Boston Scientific, he has equity stake in InBrain Pharma.

\section{Authors' Roles}

1) Research project: A. Conception, B. Organization, C. Execution;

2) Statistical Analysis: A. Design, B. Execution, C. Review and Critique;

3) Manuscript: A. Writing of the first draft, B. Review and Critique.

DD: 1A,B,C, 3A,B

EH: 1A,B,C, 3B

RW: 1A,B,C, 3B

\section{References}

1. Lang AE, Lozano AM. Parkinson's disease. Two parts. N Engl J Med. 1998;339:1044-53 \& 1130-43.

2. Langston JW. The Parkinson's complex: Parkinsonism is just the tip of the iceberg. Ann Neurol. 2006;59:591-596.

3. Dauer W, Przedborski S. Parkinson's disease: Mechanisms and models. Neuron. 2003;39: 889-909.

4. Bové J, Zhou C, Jackson-Lewis V, Taylor J, Chu Y, Rideout HJ, Wu DC, Kordower JH, Petrucelli L, Przedborski S. Proteasome inhibition and Parkinson's disease modeling. Ann Neurol. 2006;60:260-4.

5. Michel PP, Hirsch EC, Hunot S. Understanding Dopaminergic Cell Death Pathways in Parkinson Disease. Neuron. 2016;90:675-91.

6. Espay AJ, Kalia LV, Gan-Or Z, Williams-Gray CH, Bedard PL, Rowe SM, Morgante F, Fasano A, Stecher B, Kauffman MA, Farrer MJ, Coffey CS, Schwarzschild MA, Sherer T, Postuma RB, Strafella AP, Singleton AB, Barker RA, Kieburtz K, Olanow CW, Lozano A, Kordower JH, Cedarbaum JM, Brundin P, Standaert DG, Lang AE. Disease modification and biomarker development in Parkinson disease: Revision or reconstruction? Neurology. 2020;94:481-494. 
7. Hernandez DG, Reed X, Singleton AB. Genetics in Parkinson disease: Mendelian versus non-Mendelian inheritance. J Neurochem. 2016;139 Suppl 1:59-74.

8. Billingsley KJ, Bandres-Ciga S, Saez-Atienzar S, Singleton AB. Genetic risk factors in Parkinson's disease. Cell Tissue Res. 2018; 373: 9-20.

9. Singleton A, Hardy J. The Evolution of Genetics: Alzheimer's and Parkinson's Diseases. Neuron. 2016;90:1154-1163.

10. Larsen SB, Hanss Z, Kruger R. The genetic architecture of mitochondrial dysfunction in Parkinson's disease. Cell Tissue Res 2018;373:21-37.

11. Manolio TA, Collins FS, Cox NJ, Goldstein DB, Hindorff LA, Hunter DJ, et al. Finding the missing heritability of complex diseases. Nature 2009;461:747.

12. Elbaz A, Carcaillon L, Kab S, Moisan F. Epidemiology of Parkinson's disease. Rev Neurol. 2016;172:14-26.

13. Elbaz A, Clavel J, Rathouz PJ, et al. Professional exposure to pesticides and Parkinson disease. Ann Neurol.2009;66: 494-504.

14. Tanner CM, Ross GW, Jewell SA, et al. Occupation and risk of parkinsonism: a multicenter case-control study. Arch Neurol. 2009;66:1106-1113.

15. Van Maele-Fabry G, Hoet P, Vilain F, Lison D. Occupational exposure to pesticides and Parkinson's disease: A systematic review and meta-analysis of cohort studies. Environ Int. 2012;46:30-43.

16. Vingerhoets FJ1, Snow BJ, Tetrud JW, Langston JW, Schulzer M, Calne DB. Positron emission tomographic evidence for progression of human MPTP-induced dopaminergic lesions. Ann Neurol. 1994;36:765-70.

17. Pezzoli G, Barbieri S, Ferrante C, Zecchinelli A, Foà V. Parkinsonism due to n-hexane exposure. Lancet. 1989;2:874.

18. Caparros-Lefebvre D, Elbaz A. Possible relation of atypical parkinsonism in the French West Indies with consumption of tropical plants: a case-control study. Caribbean Parkinsonism Study Group. Lancet. 1999;354:281-6.

19. Hernan MA, Takkouche B, Caamano-Isorna F, Gestal- Otero JJ. A meta-analysis of coffee drinking, cigarette smoking, and the risk of Parkinson's disease. Ann Neurol 2002;52:27684.

20. Parain K, Hapdey C, Rousselet E, Marchand V, Dumery B, Hirsch EC. Cigarette smoke and nicotine protect dopaminergic neurons against the 1-methyl-4-phenyl-1,2,3,6tetrahydropyridine Parkinsonian toxin. Brain Res. 2003;984:224-32. 
21. Gagne JJ, Power MC. Anti-inflammatory drugs and risk of Parkinson disease: a metaanalysis. Neurology 2010;74:995-1002.

22. Postuma RB, Poewe W, Litvan I, Lewis S, Lang AE, Halliday G, Goetz CG, Chan P, Slow E, Seppi K, Schaffer E, Rios-Romenets S, Mi T, Maetzler C, Li Y, Heim B, Bledsoe IO, Berg D. Validation of the MDS clinical diagnostic criteria for Parkinson's disease. Mov Disord. 2018;33:1601-1608.

23. Berg D, Adler CH, Bloem BR, Chan P, Gasser T, Goetz CG, Halliday G, Lang AE, Lewis S, Li Y, Liepelt-Scarfone I, Litvan I, Marek K, Maetzler C, Mi T, Obeso J, Oertel W, Olanow CW, Poewe W, Rios-Romenets S, Schäffer E, Seppi K, Heim B, Slow E, Stern M, Bledsoe IO, Deuschl G, Postuma RB. Movement disorder society criteria for clinically established early Parkinson's disease. Mov Disord. 2018;33:1643-1646.

24. Marek K, Seibyl J, Eberly S, et al. Longitudinal follow-up of SWEDD subjects in the PRECEPT Study. Parkinson Study Group PRECEPT Investigators. Neurology 2014;82:1791-1797.

25. Antonini A, Biundo R. Parkinson disease: Can dopamine transporter imaging define early PD? Nat Rev Neurol 2014;10:432-433.

26. Marras C, Rochon P, Lang AE. Predicting motor decline and disability in Parkinson disease: a systematic review. Arch Neurol. 2002;59:1724-8.

27. Post B, Merkus MP, de Haan RJ, Speelman JD; CARPA Study Group. Prognostic factors for the progression of Parkinson's disease: a systematic review. Mov Disord. 2007;22:183951.

28. Mestre TA, Eberly S, Tanner C, Grimes D, Lang AE, Oakes D, Marras C. Reproducibility of data-driven Parkinson's disease subtypes for clinical research. Parkinsonism Relat Disord. 2018;56:102-106.

29. Luz M, Whone A, Bassani N, Wyse R, Stebbins G, Mohr E. The Parkinson's Disease Comprehensive Response (PDCORE): a composite approach integrating three standard outcome measures. Brain Communications, fcaa046

30. de la Fuente-Fernández R1, Schulzer M, Kuramoto L, Cragg J, Ramachandiran N, Au WL, Mak E, McKenzie J, McCormick S, Sossi V, Ruth TJ, Lee CS, Calne DB, Stoessl AJ. Agespecific progression of nigrostriatal dysfunction in Parkinson's disease. Ann Neurol. 2011;69:803-10.

31. Fearnley JM, Lees AJ. Ageing and Parkinson's disease: substantia nigra regional selectivity. Brain. 1991;114:2283-301. 
32. Bernheimer H, Birkmayer W, Hornykiewicz O, Jellinger K, Seitelberger F. Brain dopamine and the syndromes of Parkinson and Huntington. Clinical, morphological and neurochemical correlations. J Neurol Sci. 1973;20:415-55.

33. Braak H, Del Tredici K, Rüb U, de Vos RA, Jansen Steur EN, Braak E. Staging of brain pathology related to sporadic Parkinson's disease. Neurobiol Aging. 2003;24:197-211.

34. Selikhova M, Williams DR, Kempster PA, Holton JL, Revesz T, Lees AJ.A clinicopathological study of subtypes in Parkinson's disease. Brain. 2009;132:2947-57.

35. Berg D, Postuma RB. From Prodromal to Overt Parkinson's Disease: Towards a New Definition in the Year 2040. J Parkinsons Dis. 2018;8:S19-S23.

36. Tolosa E, Vilas D. Peripheral synuclein tissue markers: a step closer to Parkinson's disease diagnosis. Brain 2015;138:2120-2.

37. Noyce AJ, Lees AJ1, Schrag AE. The prediagnostic phase of Parkinson's disease. J Neurol Neurosurg Psychiatry 2016;87:871-8.

38. Mollenhauer B, Caspell-Garcia CJ, Coffey CS, Taylor P, Singleton A, Shaw LM, Trojanowski JQ, Frasier M, Simuni T, Iranzo A, Oertel W, Siderowf A, Weintraub D, Seibyl J, Toga AW, Tanner CM, Kieburtz K, Chahine LM, Marek K, Galasko D; PPMI study. Longitudinal analyses of cerebrospinal fluid $\alpha$-Synuclein in prodromal and early Parkinson's disease. Mov Disord. 2019;34:1354-1364.

39. Kordower JH, Olanow CW, Dodiya HB, et al. Disease duration and the integrity of the nigrostriatal system in Parkinson's disease. Brain 2013;136:2419-2431.

40. Espay AJ, Brundin P, Lang AE. Precision medicine for disease modification in Parkinson disease. Nat Rev Neurol 2017;13:119- 126.

41. Braak H, Rub U, Gai WP, Del Tredici K. Idiopathic Parkinson's disease: possible routes by which vulnerable neuronal types may be subject to neuroinvasion by an unknown pathogen. J Neural Trans 2003;110:517-536.

42. Lang AE, Espay AJ. Disease Modification in Parkinson's Disease: Current Approaches, Challenges, and Future Considerations. Mov Disord. 2018;33:660-677.

43. Rascol O, "Disease-modification" trials in Parkinson disease: target populations, endpoints and study design. Neurology 2009; 72(7 Suppl):S51-S58.

44. Van der Schyf CJ., Rational drug discovery design approaches for treating Parkinson's disease, Expert Opin Drug Discov 2015;10: 713-741.

45. Thibault L, Rascol O, Corvol JC, Ferreira J, Defebvre L, Deplanque D, Bordet R, Moreau C, Devos D. New perspectives on study designs for evaluating neuroprotection in Parkinson's disease. Mov Disord. 2017;32:1365-1370. 
46. Arribarat G, Péran P. Quantitative MRI markers in Parkinson's disease and parkinsonian syndromes. Curr Opin Neurol. 2020;33:222-229.

47. Eckert T, Tang C, Eidelberg D. Assessment of the progression of Parkinson's disease: a metabolic network approach. Lancet Neurol. 2007;6:926-32.

48. Kalia LV, Lang AE, Hazrati LN, et al. Clinical correlations with Lewy body pathology in LRRK2-related Parkinson disease. JAMA Neurol 2015;72:100-105.

49. Parkkinen L, O'Sullivan SS, Collins C, et al. Disentangling the relationship between Lewy bodies and nigral neuronal loss in Parkinson's disease. J Parkinsons Dis 2011;1:277-286.

50. Patterson L, Rushton SP, Attems J, Thomas AJ, Morris CM. Degeneration of dopaminergic circuitry influences depressive symptoms in Lewy body disorders. Brain Pathol 2019;29:544-557.

51. Irwin DJ, Grossman M, Weintraub D, et al. Neuropathological and genetic correlates of survival and dementia onset in synucleinopathies: a retrospective analysis. Lancet Neurol 2017;16:55-65.

52. Buchman AS, Yu L, Wilson RS, et al. Progressive parkinsonism in older adults is related to the burden of mixed brain pathologies. Neurology 2019;92:e1821-e1830.

53. Visanji NP, Lang AE, Kovacs GG. Beyond the synucleinopathies: alpha synuclein as a driving force in neurodegenerative comorbidities. Translational neurodegeneration 2019;8:28.

54. Espay AJ, Vizcarra JA, Marsili L, et al. Revisiting protein aggregation as pathogenic in sporadic Parkinson and Alzheimer diseases. Neurology 2019;92:329-337.

55. Galluzzi L, Vitale I, Aaronson SA, Abrams JM, Adam D, Agostinis P, et al. Molecular mechanisms of cell death: recommendations of the nomenclature committee on cell death 2018. Cell Death Differ. 2018;25:486-541

56. Do Van B, Gouel F, Jonneaux A, Timmerman K, Gelé P, Pétrault M, Bastide M, Laloux C, Moreau C, Bordet R, Devos D, Devedjian JC. Ferroptosis, a newly characterized form of cell death in Parkinson's disease that is regulated by PKC. Neurobiol Dis. 2016;94:169-78.

57. Guiney S, Adlard P, Bush A, Finkelstein D, Ayton S. Ferroptosis and cell death mechanisms in Parkinson's disease. Neurochem Int. 2017;104:34-48.

58. Kam TI, Mao X, Park H, Chou SC, Karuppagounder SS, Umanah GE, Yun SP, Brahmachari S, Panicker N, Chen R, Andrabi SA, Qi C, Poirier GG, Pletnikova O, Troncoso JC, Bekris LM, Leverenz JB, Pantelyat A, Ko HS, Rosenthal LS, Dawson TM, Dawson VL. Poly(ADP-ribose) drives pathologic $\alpha$-synuclein neurodegeneration in Parkinson's disease. Science. 2018;362(6414):eaat8407. 
59. Cao J, Chen X, Jiang L, Lu B, Yuan M, Zhu D, Zhu H, He Q, Yang B, Ying M. DJ-1 suppresses ferroptosis through preserving the activity of S-adenosyl homocysteine hydrolase. Nat Commun. 2020;11:1251.

60. Wu Z, Geng Y, Lu X, Shi Y, Wu G, Zhang M, Shan B, Pan H, Yuan J. Chaperone-mediated autophagy is involved in the execution of ferroptosis. Proc Natl Acad Sci U S A. 2019;116:2996-3005.

61. Liu Y, Wang Y, Liu J, Kang R, Tang D. Interplay between MTOR and GPX4 signaling modulates autophagy-dependent ferroptotic cancer cell death. Cancer Gene Ther. 2020 May 27.

62. Höglinger G, Carrard G, Michel P, Medja F, Lombès A, Ruberg M, Friguet B, Hirsch E. Dysfunction of mitochondrial complex I and the proteasome: interactions between two biochemical deficits in a cellular model of Parkinson's disease. J Neurochem. 2003;86:1297-307.

63. https://clinicaltrials.gov/ct2/show/NCT03127514

64. Yacoubian T, Standaert D. Targets for neuroprotection in Parkinson's disease. Biochim Biophys Acta 2009;1792:676-87.

65. Slanzi A, Iannoto G, Rossi B, Zenaro E, Constantin G. In vitro Models of Neurodegenerative Diseases. Front Cell Dev Biol. 2020;8:328.

66. Cenci MA, Björklund A. Animal models for preclinical Parkinson's research: An update and critical appraisal. Prog Brain Res. 2020;252:27-59.

67. Carvey PM, Chang Q, Lipton JW, Ling Z. Prenatal exposure to the bacteriotoxin lipopolysaccharide leads to long-term losses of dopamine neurons in offspring: a potential, new model of Parkinson's disease. Front Biosci. 2003;8:s826-37.

68. Kolb B1, Teskey GC. Age, experience, injury, and the changing brain. Dev Psychobiol. 2012;54:311-25.

69. Adolfsson R, Gottfries CG, Roos BE, Winblad B. Post-mortem distribution of dopamine and homovanillic acid in human brain, variations related to age, and a review of the literature. J Neural Transm. 1979;45:81-105.

70. Loeffler DA, Connor JR, Juneau PL, et al. Transferrin and iron in normal, Alzheimer's disease, and Parkinson's disease brain regions. J Neurochem 1995;65:710-6.

71. Kairalla JA, Coffey CS, Thomann MA, Muller KE. Adaptive trial designs: a review of barriers and opportunities. Trials 2012;13:145. 
72. Park JH, Siden E, Zoratti MJ, Dron L, Harari O, Singer J, Lester RT, Thorlund K, Mills EJ. Systematic review of basket trials, umbrella trials, and platform trials: a landscape analysis of master protocols Trials. 2019;20:572.

73. Zeissler ML, Li V, Parmar MKB, Carroll CB. Is It Possible to Conduct a Multi-Arm MultiStage Platform Trial in Parkinson's Disease: Lessons Learned from Other Neurodegenerative Disorders and Cancer. J Parkinsons Dis. 2020;10:413-428.

74. Olanow CW., Hauser RA., Jankovic J., et al. A randomized, double-blind, placebocontrolled, delayed start study to assess rasa- giline as a disease modifying therapy in Parkinson's disease (the ADAGIO study): rationale, design. Mov Disord 2008;23:21942201.

75. Odin P, Chaudhuri KR, Volkmann J, Antonini A, Storch A, Dietrichs E, Pirtošek Z, Henriksen T, Horne M, Devos D, Bergquist F. Viewpoint and practical recommendations from a movement disorder specialist panel on objective measurement in the clinical management of Parkinson's disease. NPJ Parkinsons Dis. 2018;4:14.

76. Faucheux BA, Bonnet AM, Agid Y, Hirsch EC. Blood vessels change in the mesencephalon of patients with Parkinson's disease. Lancet. 1999;353:981-2.

77. Barcia C, Bautista V, Sánchez-Bahillo A, Fernández-Villalba E, Faucheux B, Poza y Poza M, Fernandez Barreiro A, Hirsch E C, Herrero M-T. Changes in vascularization in substantia nigra pars compacta of monkeys rendered parkinsonian. J Neural Transm (Vienna) 2005;112:1237-48.

78. Ohlin KE, Sebastianutto I, Adkins CE, Lundblad C, Lockman PR, Cenci MA. Impact of LDOPA treatment on regional cerebral blood flow and metabolism in the basal ganglia in a rat model of Parkinson's disease. Neuroimage. 2012;61:228-39.

79. Pires, P.C.; Santos, A.O. Nanosystems in nose-to-brain drug delivery: A review of nonclinical brain targeting studies. J. Control. Release 2017;270:89-100.

80. Dholkawala F, Voshavar C, Dutta AK. Synthesis and characterization of brain penetrant prodrug of neuroprotective D-264: Potential therapeutic application in the treatment of Parkinson's disease. Eur J Pharm Biopharm. 2016;103:62-70.

81. Georgieva, J.V.; Hoekstra, D.; Zuhorn, I.S. Smuggling drugs into the brain: An overview of ligands targeting transcytosis for drug delivery across the blood-brain barrier. Pharmaceutics 2014;6:557-583.

82. Gaudin A, Yemisci M, Eroglu H, Lepetre-Mouelhi S, Turkoglu OF, Dönmez-Demir B, Caban S, Sargon MF, Garcia-Argote S, Pieters G, Loreau O, Rousseau B, Tagit O, Hildebrandt N, Le Dantec Y, Mougin J, Valetti S, Chacun H, Nicolas V, Desmaële D, 
Andrieux K, Capan Y, Dalkara T, Couvreur P. Squalenoyl adenosine nanoparticles provide neuroprotection after stroke and spinal cord injury. Nat Nanotechnol. 2014;9:1054-1062.

83. Mursaleen L, Noble B, Stefanie Ho Y Chan S, Somavarapu S and Zariwala1 M. NAcetylcysteine Nanocarriers Protect against Oxidative Stress in a Cellular Model of Parkinson's Disease. Antioxidants (Basel). 2020;9: 600.

84. He Q, Liu J, Liang J, Liu X, Li W, Liu Z, Ding Z, Tuo D. Towards Improvements for Penetrating the Blood-Brain Barrier-Recent Progress from a Material and Pharmaceutical Perspective. Cells. 2018;7.pii: E24.

85. Hasnat MJ1, Rice JE. Intrathecal baclofen for treating spasticity in children with cerebral palsy. Cochrane Database Syst Rev. 2015;11:CD004552.

86. Paul G, Zachrisson O, Varrone A, Almqvist P, Jerling M, Lind G, Rehncrona S, Linderoth B, Bjartmarz H, Shafer LL, Coffey R, Svensson M, Mercer KJ, Forsberg A, Halldin C, Svenningsson P, Widner H, Frisén J, Pålhagen S, Haegerstrand A. Safety and tolerability of intracerebroventricular PDGF-BB in Parkinson's disease patients. J Clin Invest. 2015;125:1339-46

87. Burgess A, Shah K, Hough O, Hynynen K. Focused ultrasound-mediated drug delivery through the blood-brain barrier. Expert Rev Neurother. 2015;15:477-91.

88. Le Floc'h J, Lu HD, Lim TL, Démoré C, Prud'homme RK, Hynynen K, Foster FS. Transcranial Photoacoustic Detection of Blood-Brain Barrier Disruption Following Focused Ultrasound-Mediated Nanoparticle Delivery. Mol Imaging Biol. 2020;22:324-334

89. Dickson M, Gagnon JP. Key factors in the rising cost of new drug discovery and development. Nat Rev Drug Discov. 2004;3:417-29.

90. Devos D, Moreau C, Devedjian JC, Kluza J, Petrault M, Laloux C, Jonneaux A, Ryckewaert G, Garçon G, Rouaix N, Duhamel A, Jissendi P, Dujardin K, Auger F, Ravasi L, Hopes L, Grolez G, Firdaus W, Sablonnière B, Strubi-Vuillaume I, Zahr N, Destée A, Corvol JC, Pöltl D, Leist M, Rose C, Defebvre L, Marchetti P, Cabantchik ZI, Bordet R. Targeting chelatable iron as a therapeutic modality in Parkinson's disease. Antioxid Redox Signal. 2014;21:195-210.

91. Moreau C, Duce JA, Rascol O, Devedjian JC, Berg D, Dexter D, Cabantchik ZI, Bush AI, Devos D; FAIRPARK-II study group. Iron as a therapeutic target for Parkinson's disease. Mov Disord. 2018;33:568-574. www.fairpark2.eu

92. McFarthing K, Buff S, Rafaloff. G, Dominey T, Wyse R, Stott S. Parkinson's disease drug therapies in the clinical trial pipeline: 2020. J Parkinsons Dis. 2020;10:757-774. 


\section{Legends}

\section{Figure 1: Past and current therapeutic strategies illustrating the need of biomarkers of} target engagements

Main physiopathological mechanisms (orange boxes) with complex and multiple interplays (arrows to show that they are in fact all connected), failed past therapeutic strategies (light blue boxes), strategies currently in clinical trials (dark blue boxes). (sources: ${ }^{42,92}$ and www.clinicaltrials.gov). None of the past and failed trials matched the therapies tested with the suitable molecular biology of the intended recipients. Thus, there is an urgent need of biomarkers that can demonstrate the molecular susceptibility to the mechanism of the drugs in order to validate target engagement and to assess drug response in patients.

Figure 2: Vocabulary of treatment modalities according to (a) the impact on the neuronal count in preclinical models and (b) on the clinical handicap progression in patients.

\section{Figure 3: Seven solutions}

Organization of seven interconnected solutions of varying importance that can be exclusive or additive and outline approaches to help generate successful development of efficient treatments aiming at reducing the rate of downward trajectory of disease progression.

Abbreviations: PD: Parkinson's disease 


\title{
Seven solutions for neuroprotection in Parkinson's disease
}

\author{
David Devos $\mathrm{MD}, \mathrm{PhD}^{(1)^{*}}$, Etienne Hirsch $\mathrm{PhD}^{(2)^{*}}$, Richard Wyse $\mathrm{PhD}^{(3)^{*}}$ \\ (1) University of Lille, Department of Medical Pharmacology, Expert center for \\ Parkinson, CHU-Lille, Lille Neuroscience \& Cognition, Inserm, UMR-S1172, \\ LICEND, NS-Park network, France \\ (2) Institut du Cerveau - ICM, Inserm U 1127, CNRS UMR 7225, Sorbonne Université, \\ F-75013, Paris, France \\ (3) The Cure Parkinson's Trust, London, UK \\ * Authors equally contributed
}

Corresponding authors: Devos David \& Etienne Hirsch

david.devos@chru-lille.fr ; etienne.hirsch@upmc.fr

ORCID numbers:

David Devos: 0000-0002-2417-799X

Etienne Hirsch: 0000-0003-4823-276X

Richard Wyse: 0000-0001-9542-5033X

Running title: Neuroprotection in Parkinson's disease

Keywords: Parkinson's disease - drug development - preclinical studies - clinical trial neuroprotection - disease-modifying effect.

Title: 58 characters including space, running title: 39 characters including space, Abstract: 160 words, text: 4799 words; Figure: 3; references: 92 


\begin{abstract}
Parkinson's disease (PD) is a neurodegenerative disorder characterized by loss of dopaminergic neurons in the substantia nigra, and accumulation of iron and alpha-synuclein; it follows a characteristic pattern throughout the nervous system. Despite, decades of successful preclinical neuroprotective studies, no drug has then shown efficacy in clinical trials. Considering this dilemma, we have reviewed and organized solutions of varying importance that can be exclusive or additive and outline approaches to help generate successful development of neuroprotective drugs for PD: 1) select patients in which the targeted mechanism is involved in the pathological process associated with the monitoring of target engagement; 2) combine treatments that target multiple pathways; 3) establish earliest interventions and develop better prodromal biomarkers; 4) adopt rigorous methodology and specific disease-relevant designs for disease-modifying clinical trials; 5) customize drug with better brain biodistribution; 6) prioritize repurposed drugs as a first line approach; 7) adapt preclinical models to the targeted mechanisms with translational biomarkers to increase their predictive value.
\end{abstract}




\section{Introduction}

Parkinson's disease (PD) is a complex neuropsychiatric disorder. ${ }^{1,2}$ It is a progressive and topographically extensive neurodegenerative disease, with a classical pathological hallmark that involves dopaminergic neuron regulated cell death, notably in the substantia nigra pars compacta (SNpc). It is associated with iron accumulation, oxidative stress, nitrosative stress, lipid peroxidation, neuro-inflammation, glutamate excitotoxicity, mitochondrial deficits, lysosome and proteasome alteration with protein misfolding notably of alpha synuclein ( $\alpha$-syn) with aggregates. ${ }^{3-5}$

Many preclinical studies have identified efficient therapeutic strategies that work well in animal models of PD, but so far, none of them has been confirmed to be effective in clinical trials in patients (Figure 1). Consequently, many pharmaceutical and biotechnology companies have been reluctant to enter or even remain in the field of PD drug development. One conceivable fundamental problem for the repetitive failure to convert positive pre-clinical results into therapeutic success might be that PD does not consist of a single disorder, but rather, it consists of a syndrome that shares only weak biologic commonalities and thus requires a careful molecular and clinical triage. 6

Another major difficulty in developing clinical trials for neuroprotection is the fact that the brain is not accessible for in vivo neuronal counts, and therefore there are no tools in the clinic capable of monitoring neuroprotection. Consequently, the term "disease modifier" was introduced in the field (Figure 2). The concept of a disease modifying agent implies that it is able to demonstrate a tangible impact on molecular mechanisms known to be involved in the degenerative process. Currently, many of these cannot be fully demonstrated in patients due to limitations in brain accessibility, and the lack of suitable biochemical imaging markers. In this review, we identify and discuss seven current limiting factors of neuroprotective strategies and propose solutions for each of these to help develop efficient treatments aiming at reducing the rate of downward trajectory of disease progression in PD (Figure 3). Importantly, these solutions are not of equal importance, some of them being exclusive and others additive.

\section{Search strategy and selection criteria}

To the best of our knowledge, there is no review describing the strategies required for a translational development of a treatment for neuroprotection in PD. References for this review 
were identified by searches of PubMed between 1969 and July 2020. The search terms were guided by two strategies: 1) recent reviews on each topic and 2) examples to illustrate the concepts and the solutions.

\section{Challenge 1: PD is not just "heterogeneous" or "complex" but a syndrome.}

PD belongs to the wide range of complex multifactorial and polygenic disorders influenced both by genetic and environmental factors, and is very likely a combination of both in a large proportion of PD patients. Less than $10 \%$ of PD cases have a monogenic origin. The known causal mutations affect 15 genes and explain only about $30 \%$ of monogenic (and 3-5\% of sporadic) cases. ${ }^{6}$ Moreover, the monogenic forms display a variable penetrance, variable expression and a very long pre-symptomatic phase, suggesting that other causal and risk factors are involved in the pathogenesis. Unbiased genome-wide association studies (GWAS) have demonstrated a role of more common genetic variants, leading to the concept of 'graded risk', which is a continuum from Mendelian mutations, low frequency disease-causing mutations, and common polymorphisms with an associated strong-to-low impact on the disease expression and progression. ${ }^{7-11}$ A similar level of complexity of provenance applies to our understanding of the environmental toxic causes of PD. ${ }^{12}$ Exposure to pesticides have been reported to increase the risk of developing PD, especially for farmers employing organo-chloride chemicals, ${ }^{13-15}$ exposure to MPTP ${ }^{16}$, and intoxication by n-hexane, ${ }^{17}$ atypical French Caribbean Parkinsonism. ${ }^{18}$ Noteworthy, most of these environmental compounds are inhibitors of mitochondrial complex 1, which suggests this as a specific pathway of neurodegeneration. This complicated situation might be made even more complex due to the behavioral consumption of substances during one's lifetime that might themselves also alter PD progression. Indeed, the risk of developing PD has been shown to be lower in smokers than in non-smokers, ${ }^{19,20}$, or in individuals treated by anti-inflammatory drugs such as Ibuprofen. ${ }^{21}$ Consequently, it is important to consider the various etiologies and risk factors of PD on one hand whilst, on the other hand, also actively consider the positive and negative risk factors that influence the rate of disease progression. A major limitation of most neuroprotective PD clinical trials is that the precise etiology of the disease, and the prior individual environmental exposures of the patients recruited into these studies, remains unknown.

\section{Solution 1: To develop clinical trials on patients with known etiology and risk factors}

In a diabetic patient, no one would prescribe anti-diabetic drugs without considering the patient's dependency on taking insulin. However, it is exactly this type of mistake we are 
making in the field of PD by including patients with mixed etiologies in neuroprotection trials. There is now a clear need for changing the strategy and performing clinical trials on wellcharacterized populations of patients. Despite the small number of patients with a genetic origin of their disease, clinical trials should be developed on populations of patients with identical mutations. Furthermore, the diagnosis of PD should be validated by combining specific clinical criteria (MDS) 22,23 and imaging of dopamine depletion for inclusion criteria of de novo patients. ${ }^{24,25}$ This is especially important in carriers of PD causative mutations, as they might still be in a presymptomatic stage of the disease. Furthermore, because in patients with identical mutations the clinical and pathological expression of the disease might vary, ${ }^{7,9}$ selecting more homogenous subpopulations according to the rate of progression of the disease and prognosis factors should be the gold standard. Indeed, in de novo patients, probable predictors of more rapid motor decline and disability could be used - such as higher age at onset, baseline motor impairment with higher postural instability, and gait disorders score (non-tremor dominant subtype), cognitive impairment and depression. ${ }^{26,27}$ However, specific criteria validated with a rigorous approach on large cohorts are still lacking. ${ }^{28}$

Even patients with exactly the same mutation can display different phenotypes. This is very likely due to different environmental exposures during life, as well as incomplete penetrance. Thus, the concept of 'graded risk' developed from genetic research needs to associate the environment causes and risk factors. The genetic approaches that identify very rare causative mutations underlying monogenic forms and common variants with small effects need to be associated with questionnaires and biological samples for environmental factors, ${ }^{12-19}$ the comorbidities, and the antiparkinsonian and other treatments. By comparing large cohorts of patients and controls, machine learning and deep learning might allow stratifying the various subpopulations according to the risk factors of developing PD with omics and epigenetic analyses to develop the future biomarkers of patient stratification for upcoming trials. ${ }^{8}$ The same strategy needs to be developed on longitudinal cohorts of patients with respect to the accurate selection of trial end points of disease progression, or time to chosen milestones, or the novel weighted composite endpoint (PDCORE) ${ }^{29}$.

Altogether, a better characterization of the patients in terms of the causes and the factors of their disease progression will lead to a better stratification and to reduce patient variability in order to improve the statistical accuracy of the outcomes and end-points measured (Figure 3).

\section{Challenge 2: Targeting single pharmacological pathways is not efficient}


The mechanisms leading to neurodegeneration in PD include multiple pathways. ${ }^{3-5}$ Ultimately, neurons die by regulated cell death. However, 14 separate types of cell death have now been defined. ${ }^{55}$ Apoptosis, ferroptosis, necroptosis, autophagy and parthanatosis (target of rapamycin (mTOR) poly (ADP-ribose) (PAR) polymerase-1 (PARP-1)) appear to be particularly relevant for PD. ${ }^{56-59}$ Yet, further studies are required to better characterize the exact types of cell death that are most relevant in PD neurodegeneration. Importantly, recent research in cancer has demonstrated that, while there are distinct individual forms of cell death involved, they also display key connections between them, notably between ferroptosis, autophagy and parthanatosis. ${ }^{60,61}$ In addition, whether these molecular and cellular interactions represent a cause or a consequence of neurodegeneration in PD still needs clarification. An important issue for developing efficient neuroprotective trials is to determine whether the molecular changes involved actually belong to the same molecular pathways or instead to parallel pathways (i.e. different pathways). Of course, a broad action on several pathways will largely increase the chance of success.

\section{Solution 2: Identify all PD-relevant pathways of cell death and combine treatments that target multiple pathways}

Identifying the interactions between the molecular and cellular changes seen in PD is a key requirement in terms of informing how best to establish robust neuroprotection. Of course, if they belong to the same pathway blocking the deleterious mechanism, whether upstream or downstream to these molecular targets, this will result in the same protective effect and a single drug might therefore likely be highly efficient. On the other hand, if they belong to parallel pathways, then blocking one of these will not result in neuroprotection since the deleterious effects of the other pathway will still contribute to the neurodegenerative process. It has been exemplified in experimental models of PD that mitochondrial complex 1 deficiency and proteasome dysfunction belong to parallel pathways. ${ }^{62}$ Thus, if this is similarly true in human pathology, then disease-modifying clinical trials will require a combination of two or more drugs, and thereby targeting multiple pathways involved in neurodegeneration. Alternately, one might consider using drugs with a pleiotropic action, or using an appropriate combination of drugs. Yet, drug agencies still require proof of efficacy of each single drug - as monotherapies - before approving the development of any combinations of these drugs. But such a multi-drug strategy has already been proven to be highly successful in the fields of cancer, HIV and tuberculosis. Future neuroprotective strategies in PD should similarly test combinations of drugs selected on the basis of the various relevant mechanisms of cell death in any given 
subtype of PD. This strategy has recently started in amyotrophic lateral sclerosis with a combination of two drugs already in use (sodium phenylbutyrate and tauroursodeoxycholic acid). ${ }^{63}$ However, this strategy will not overcome the problem of whether any of the pathways targeted are truly at play in the population recruited for those trials.

\section{Challenge 3: Neuroprotective interventions are initiated too late in the course of the disease}

Most clinical trials are started a few years after the onset of symptoms, partly to ensure all enrolled patients have a reliable diagnosis of PD. Yet, imaging studies of dopaminergic markers have estimated there is a preclinical period of 15 to 20 years in younger, and 10 years in older, PD patients. ${ }^{30}$ By the time motor symptoms appear, patients have, lost 80 percent of their striatal dopamine, corresponding to $50 \%$ loss of dopaminergic neurons in the substantia nigra..$^{31,32}$ Additionally, neuropathological examinations have, years before the SNpc is affected, shown lesions in the olfactory bulb, mesenteric plexus, brainstem including locus coeruleus, and raphe nucleus. ${ }^{16,33}$ Finally, the neurodegenerative process might by itself engage a self-perpetuating phenomenon as shown in the human subjects intoxicated by MPTP. Thus, it is clear that late therapeutic intervention obviously decreases the chance of success.

\section{Solution 3: To establish early interventions and develop better prodromal biomarkers}

The prodromal phase is theoretically the best period to start any neuroprotective treatment, and it should ideally be initiated before any important damage of the nigro-striatal pathway has occurred corresponding to the first stages (1 and 2) of Braak's classification. ${ }^{33}$ However, there are two major limitations. i) The spectrum of symptoms during these early Braak's stages remains complex and very variable among patients. ${ }^{34,35}$ ii) Some individuals recruited during the prodromal phase may not express the disease, or may only develop it very late. This calls for a search of better diagnosis biomarkers (wet, dry, wearable) during the prodromal phase of the disease, and incorporating likelihood ratios with age and gender (of developing overt PD), and improved predictive algorithms generated by big data approaches to predict the likelihood of progression into the symptomatic phase. ${ }^{35-38}$

Until now de novo patients have constituted the best population for neuroprotective trials, with the aim that the remaining dopaminergic neurons can be saved. ${ }^{39-42}$ Furthermore, at this stage, there is no interference of dopaminergic treatment on the analysis of any neuroprotective effect. However, it is difficult to recruit de novo patients for several reasons. 1) There is a risk of 
including atypical forms and lack of dopamine depletion. 2) There is a higher patient dropout rate because patients are stressed, or in denial, after receiving their diagnosis, and may poorly tolerate the lack of symptomatic treatment. ${ }^{42-45}$ Another alternative is to perform the trials on early PD patients (within the first 3 years after diagnosis) because they receive a stable, moderate-dose regimen of dopaminergic drugs and could still benefit from an intervention that would reduce the rate of disease progression. Furthermore, these patients are easy to recruit and allow studying the interactions between the neuroprotective compound and dopamine agonists and/or L-dopa. ${ }^{42-45}$

The ideal population of patients to include in neuroprotective trials are those characterized by a genetic trait, or by a biomarker that would confirm the diagnosis during the presymptomatic phase and that can demonstrate the molecular susceptibility to the mechanism of the drug to which it is exposed. Asymptomatic carriers of mutations causative of PD represent the best population to study. Yet, in such patients, the onset of the symptoms is very difficult to predict. One strategy would consist of performing neuroprotective trials in these patients a few years before the mean age of onset in such a specific population. The read-out of these types of neuroprotective studies would then be the "delayed time to transition" to the symptomatic phase. Yet, such patients are relatively rare and inclusion difficulties might prevent extensive clinical trials unless run as a global effort. Furthermore, because of the variability in the duration of the asymptomatic phase due to variable penetrance of the genes involved, such initiatives might also require long study durations, thereby increasing their cost. ${ }^{6,42-45}$

Because of the difficulties in performing clinical trials in inherited forms of $\mathrm{PD}$, neuroprotective approaches should also be tested in sporadic cases. To do this, there is a need for diagnostic biomarkers during the prodromal phase of the disease. Many studies have attempted to identify such wet and dry biomarkers. $6,38,40,42,43,45-48$ Among those candidates, $\alpha$-synuclein ( $\alpha$-syn) is regarded by many as the most promising. ${ }^{6,33,41}$ However, PD is usually associated with abnormal accumulation of several other types of misfolded proteins, notably $\beta$-amyloid and tau, which co-occur with $\alpha$-syn. 6,33,41 Moreover, Lewy pathology is not necessarily found in all forms of PD (e.g. some leucine-rich repeat kinase 2 (LRRK2) patients, and most of the Parkinrelated cases). ${ }^{6,48}$ Furthermore, even in cases with clear synucleinopathies, there is no dosedependent correlation between Lewy pathology, cell loss and clinical features. ${ }^{49,50}$ Consequently, $\alpha$-syn represents a convenient pathologic biomarker but may not be pathogenic with the exception of $\alpha$-syn-related genetic PD patient subtypes. ${ }^{51-54}$ Moreover, $\alpha$-syn 
determination in fluids or peripheral tissues cannot be the sole surrogate biomarker of PD because its concentration is modified by complex physiopathological responses within the body, as well as being modified by the consequences of PD neurodegeneration. Further studies are required to analyze the dynamic expression and deposition of $\alpha$-syn during PD disease progression, ideally using a translational approach.

\section{Challenge 4: The methodology of clinical trials is not adapted to progressive long-term neurodegeneration}

The design of disease-modifying, neuroprotective clinical trials in PD patients is very challenging for several reasons. First, there is no reference drug, nor any clinical trial design, that has ever shown efficiency for neuroprotection. This might be due to the lack of efficacy of the tested drugs and/or from poor clinical trial designs, or both. This problem is even more complex in PD because the tested medications might have both a symptomatic and a neuroprotective effect. Second, biomarkers of neuroprotection are still lacking and it is therefore difficult to determine on rational scientific grounds whether or not the drug being tested is actually reaching its biological target and is thereby having a positive effect at a cellular level. Thus, clinical trials mostly rely on clinical outcomes. However, the clinical symptoms are, themselves, not very sensitive to be able to demonstrate meaningful change since they do not progress rapidly enough to measure accurately, at least not over the study durations, typically 1 year, chosen for most neuroprotective clinical trials in PD patients. Third, even with well-validated scales such as UPDRS, drug testing of putative neuroprotective agents is not typically performed in a real-life environment. Finally, the global handicap (i.e. motor, cognitive and behavior), also including the rather more variable non-motor symptoms, needs to be considered. All of this, calls for new designs of neuroprotection trials in PD.

\section{Solution 4: To adopt rigorous methodology and specific disease-relevant designs for PD neuroprotective clinical trials}

It is clear that greater attention must be paid in selecting the most appropriate clinical trial design, with either an adaptation of a well-tested design, or new approach depending on any suspected possibility or likelihood that the neuroprotective drug under investigation may also have a concomitant symptomatic effect.6,42-45 (Figure 3) Adaptive trials have been also proposed as a version of the responder trial..$^{71}$ A first discovery phase includes a broad population with several subtypes followed by a validation phase considering only the best patient responders. Master protocols, including "basket trials", "umbrella trials", and "platform 
trials", use a trial network with shared infrastructure and are designed with multiple sub-studies to evaluate one or more investigational drugs in one or more disease subtypes. ${ }^{72,73}$ Following the same idea, multi-arm, multi-stage (MAMS) trials have been recently proposed to test many potential therapies currently in the pipeline in parallel (multi-arm), transitioning seamlessly through various phases (multi-stage), i.e., from a phase II safety and efficacy study to a phase III trial, with the help of a platform. ${ }^{74}$ While they are attractive, they come from the oncology field where the simultaneous therapeutic use of multiple drugs is already validated and accepted by regulatory authorities, which is far from the current case for PD.

The demonstration of the reduction of an already slow disease progression is very challenging since it requires a long-term study during which the symptomatic dopaminergic requirements of patients are frequently changing, and this can greatly confuse the interpretation of neuroprotective results. Regarding the duration of the trial, if a symptomatic treatment is not introduced or modified, a period between 6 to 12 months represents a reasonable and practical compromise between having sufficient time to observe a neuroprotective effect and the relatively limited number of patient dropouts set against an attrition of study subjects that inevitably continues to increase over longer trial durations. For example, a study duration of 6 months in de novo patients was associated with a drop-out rate of $10-15 \%$ in the ADAGIO trial. ${ }^{75}$ Conversely, a 9-month period would have a greater chance of clinical success but at the expense of a higher drop-out rate in de novo patients. ${ }^{45}$

The current MDS-UPDRS clinical scales are not designed to assess subtle modifications of disease progression. This low sensitivity to monitor change requires a very large population of patients to be followed for long periods of time, and this is very challenging for Phase II trial purposes. Using a biomarker as a primary outcome measure is an interesting alternative for an early phase II study. Objective and continuous measures offer a different perspective, with wearable technologies provide specific and rigorous quantification that could become efficient biomarkers of motor handicap in real life spanning over several days, such as, connected actimetry $^{76}$ and connected soles for a continuous recording of gait and balance.

\section{Challenge 5: Targeting the central nervous system (CNS) represents a pharmacological challenge}

Another major challenge relates to the poor blood-brain-barrier (BBB) penetration of many candidate neuroprotective drugs. The competitive and variable drug penetration in the brain parenchyma leads to low and unpredictable bio-distribution in the CNS with additional 
confounding interference from dietary foods and drug interactions etc. Furthermore, for most of the drugs there is no measurement of its concentration in the brain parenchyma, nor of its engagement with its biological target in neurons. Thus, clinicians currently only rely on clinical scales or, in the best cases, also on various available imaging parameters of the brain.

The issue of BBB drug penetration might also be challenging due to blood vessel modifications associated with the disease process or the medication 77,78

\section{Solution 5: To customize drug with better and more selective brain accessibility}

Pharmacokinetic studies with drug concentration measurements should be associated in both preclinical and clinical studies. Yet, this is complex because cerebrospinal fluid (CSF) is not accessible on a repetitive basis and only gives a biased measurement of the drug concentration in the brain region targeted by the drug. Furthermore, sampling of both CSF and blood as a function of time after administration provides an estimate the precision of which will depend on the number of samples over time. The association of brain tissue and clinical measures respectively in both the experimental models and the patients - should ideally allow the establishment of an algorithm to help select the best dose and regimen in humans.

Another need is to improve drug penetration into the brain by customizing drugs with better penetration characteristics, or by developing prodrugs that will easily cross the BBB. Indeed, oral administration is obviously the easiest, but not the best, method of drug delivery for brain diseases. Transnasal delivery is also noninvasive and easy to operate and should be considered for intermittent administration of small molecules or small volumes of drug. ${ }^{79}$ Only small and lipophilic drugs can readily penetrate into the brain. In the situation where a very effective neuroprotective drug poorly penetrates the BBB, then several options might be usefully considered to help improve its brain penetration. The first option for small molecules is to increase their lipidation, or to reduce their size, keeping only the active neuroprotective fragment. Another interesting option is to use a lipophilic prodrug. ${ }^{80,81}$ Nanoparticles represent another chemical modification to increase BBB permeability (Figure 3). ${ }^{82,83}$

If, despite chemical modification, the drug does not penetrate into the brain parenchyma then instead, direct delivery in the brain might be considered. ${ }^{84}$ The procedure involving intrathecal administration of baclofen or painkillers has been reported to be effective, reversible, and safe in thousands of patients. ${ }^{85}$ The safety of brain infusion of growth factors has also generated promising results despite a lack of efficacy for neuroprotection. ${ }^{86} \mathrm{With}$ such procedures, high 
local drug and personalized concentrations can be achieved with no or minimal systemic adverse events.

Developments using physical, chemical and biological methods to open the BBB have also emerged recently. For example, focused ultrasound (FUS) has been shown to be safe and very efficient. Such approaches represent an interesting alternative for intermittent administration of drugs with long lasting effects. ${ }^{87,88}$ Co-administration of or substances acting on the efflux carriers, and transporters, can also theoretically increase drug penetration. ${ }^{84}$

\section{Challenge 6: Neuroprotection represents a very long and risky drug development}

Developing a new drug is always very long (an average of 14.2 years), very expensive (US $\$ 802$ million) and challenging. ${ }^{89}$

\section{Solution 6: To reduce the risk of drug development for PD}

Additional safeguards need to be developed with combined efforts both from academic partners and the drug industry. Prioritizing the development of repurposed drugs represents an attractive approach for neuroprotection in PD. Drugs already on the market for other therapeutic indications have the advantage of being already used for humans, and helpfully already have a well-known safety profile. Because of the extensive experience with these compounds they are generally also straightforward to test in preclinical models. Generally, their pharmacokinetic and pharmacodynamic characteristics are known, but the issues of brain penetration and adaptation of the dosage to the CNS might not be trivial. In terms of intellectual property, a new patent of an old drug for a new indication or formulae typically allows increasing the time for development for use in another indication. Target validation and lead molecule optimization can then be developed based upon this safe, first-in-class, repurposed drug.

Another way of reducing the risk for drug development in neuroprotection is based on the fact that a few drugs may have shown efficacy in animals, and then also shown encouraging results in humans, but were subsequently abandoned because of their toxicity in a very small number of patients. Yet, even if a drug does not have an ideal safety profile, rigorous monitoring can allow testing it in clinical trials. Deferiprone is currently being clinically assessed for conservative iron chelation despite a rare risk of agranulocytosis $(<0.8 \%) .{ }^{90,91}$

\section{Challenge 7: Animal models of PD are not predictive of clinical efficacy}


No molecule that has demonstrated positive in vitro, and in vivo, effects on neuroprotection has displayed any neuroprotective effect in clinical trials. ${ }^{42,64}$

\section{Solution 7: To adapt preclinical models of PD and research design to the clinical situation}

One of the reasons for the lack of predictive value of any of the PD animal models is the fact that these models cannot recapitulate the clinical situation. Animal models can inform about mechanisms of therapy but not about patient selection for that therapy. This is why one should associate, in a translational manner, dry and wet biomarkers of the targeted mechanisms both in the models, and in humans, to ascertain neuroprotection.

The prediction of neuroprotection requires human, non-oncogenic, cell models including LUHMES, primary dopaminergic neuron culture, patient-derived Inducible Pluripotent Stem cells and three-dimensional brain organoids ${ }^{65}$.

Several in vivo models have been generated through neurotoxin-based or genetic-based approaches in rodents, or non-human primates, to demonstrate and validate neuroprotection. Neurotoxin-induced models reproduce some of the key molecular alterations such as complex 1 deficiency, or proteasomal dysfunction. Chemicals such as 6-hydroxydopamine, MPTP, rotenone, annonacine, and paraquat are mainly used to generate these types of PD models. Protein accumulation can be generated via overexpression of $\alpha$-syn. In addition, protein aggregation pathology can be triggered by inoculating preformed fibrils of $\alpha$-syn in the brain. ${ }^{66}$ Yet, a limitation of these models is that not all of the molecular changes seen in PD actually coexist in a single model. It may be useful, to increase the prediction by associating different experimentations in different in vivo models (toxin and genetic hits), to reproduce far better the full pathological process as typically seen in PD. ${ }^{66}$

Another important issue of neuroprotection trials is that, even for a same mutation, the clinical phenotypes of the patients recruited into a trial do vary considerably. Preclinical neuroprotection studies should therefore be performed using animals of mixed genetic backgrounds, and not on inbreed animals from an identical genetic provenance, but this may necessitate an increase in the required number of animals to achieve statistical significance. 
The immune status of animals is also important to monitor because neuroinflammatory processes also participate to neuronal degeneration. Indeed, most preclinical studies are performed on animals housed in a sterile environment, but PD patients in their daily lives are in constant contact with multiple immune stimulating agents. Lipopolysaccharide, a bacterial membrane molecule well known for its immune stimulating properties, increases the sensibility to parkinsonian toxins in rodents. ${ }^{67}$ Such a phenomenon might even start very early during life as offspring of pregnant rats injected with LPS are also more sensitive to parkinsonian toxins. ${ }^{67}$ One should thus consider monitoring carefully the immune status of the animals or perhaps even house the animals in standard non-SFP facilities.

Because PD is in most cases associated with aging, preclinical studies should include old animals. Indeed, elderly humans, and old animals, show less neuronal plasticity ${ }^{68}$ a lower level of dopamine metabolism ${ }^{69}$ and a higher iron content (which increases the pro-oxidant status ${ }^{70}$ ), and they also display considerably different dose-related effects to drugs given. PD is more prevalent in men, but both genders need to be accurately assessed because huge differences between them can be observed in terms of dose effects and neuronal degeneration.

The chronicity (months or even years) both of the degenerative process, and of the treatment regimen given, as well as the time at which the treatment is first introduced (ideally at time of the onset of symptoms) should be accurately reproduced in animal models.

Finally, good practice standards should be used in preclinical studies just as is the case in the clinical studies (Figure 3). Such standards are costly and will dramatically reduce the number of studies but will undoubtedly increase their predictability.

\section{Conclusion}

We have described a number of critical hurdles that are currently hampering progress towards bringing effective neuroprotective therapeutic approaches to slow disease progression in patients with Parkinson's disease, which arguably represents the greatest unmet need in this therapeutic area. We do not believe any of these hurdles are intractable and, especially considering the wealth of promising new neuroprotective approaches that are currently emerging, we have therefore outlined and organized exclusive or additive solutions of varying importance to help generate successful development of neuroprotective drugs for PD solutions and approaches to help overcome most or all of these hurdles. 


\section{Financial Disclosures of all authors (for the preceding 12 months)}

$\mathrm{DD}, \mathrm{EH}, \mathrm{RW}$ have no conflict of interest regarding the review.

DD served on several Scientific Advisory Boards for Orkyn, Air Liquide, Lundbeck, Ever Pharma and Boston Scientific, he has equity stake in InBrain Pharma.

\section{Authors' Roles}

1) Research project: A. Conception, B. Organization, C. Execution;

2) Statistical Analysis: A. Design, B. Execution, C. Review and Critique;

3) Manuscript: A. Writing of the first draft, B. Review and Critique.

DD: $1 \mathrm{~A}, \mathrm{~B}, \mathrm{C}, 3 \mathrm{~A}, \mathrm{~B}$

EH: 1A,B,C, 3B

RW: 1A,B,C, 3B

\section{References}

1. Lang AE, Lozano AM. Parkinson's disease. Two parts. N Engl J Med. 1998;339:1044-53 \& 1130-43.

2. Langston JW. The Parkinson's complex: Parkinsonism is just the tip of the iceberg. Ann Neurol. 2006;59:591-596.

3. Dauer W, Przedborski S. Parkinson's disease: Mechanisms and models. Neuron. 2003;39: 889-909.

4. Bové J, Zhou C, Jackson-Lewis V, Taylor J, Chu Y, Rideout HJ, Wu DC, Kordower JH, Petrucelli L, Przedborski S. Proteasome inhibition and Parkinson's disease modeling. Ann Neurol. 2006;60:260-4.

5. Michel PP, Hirsch EC, Hunot S. Understanding Dopaminergic Cell Death Pathways in Parkinson Disease. Neuron. 2016;90:675-91.

6. Espay AJ, Kalia LV, Gan-Or Z, Williams-Gray CH, Bedard PL, Rowe SM, Morgante F, Fasano A, Stecher B, Kauffman MA, Farrer MJ, Coffey CS, Schwarzschild MA, Sherer T, Postuma RB, Strafella AP, Singleton AB, Barker RA, Kieburtz K, Olanow CW, Lozano A, Kordower JH, Cedarbaum JM, Brundin P, Standaert DG, Lang AE. Disease modification and biomarker development in Parkinson disease: Revision or reconstruction? Neurology. 2020;94:481-494. 
7. Hernandez DG, Reed X, Singleton AB. Genetics in Parkinson disease: Mendelian versus non-Mendelian inheritance. J Neurochem. 2016;139 Suppl 1:59-74.

8. Billingsley KJ, Bandres-Ciga S, Saez-Atienzar S, Singleton AB. Genetic risk factors in Parkinson's disease. Cell Tissue Res. 2018; 373: 9-20.

9. Singleton A, Hardy J. The Evolution of Genetics: Alzheimer's and Parkinson's Diseases. Neuron. 2016;90:1154-1163.

10. Larsen SB, Hanss Z, Kruger R. The genetic architecture of mitochondrial dysfunction in Parkinson's disease. Cell Tissue Res 2018;373:21-37.

11. Manolio TA, Collins FS, Cox NJ, Goldstein DB, Hindorff LA, Hunter DJ, et al. Finding the missing heritability of complex diseases. Nature 2009;461:747.

12. Elbaz A, Carcaillon L, Kab S, Moisan F. Epidemiology of Parkinson's disease. Rev Neurol. 2016;172:14-26.

13. Elbaz A, Clavel J, Rathouz PJ, et al. Professional exposure to pesticides and Parkinson disease. Ann Neurol.2009;66: 494-504.

14. Tanner CM, Ross GW, Jewell SA, et al. Occupation and risk of parkinsonism: a multicenter case-control study. Arch Neurol. 2009;66:1106-1113.

15. Van Maele-Fabry G, Hoet P, Vilain F, Lison D. Occupational exposure to pesticides and Parkinson's disease: A systematic review and meta-analysis of cohort studies. Environ Int. 2012;46:30-43.

16. Vingerhoets FJ1, Snow BJ, Tetrud JW, Langston JW, Schulzer M, Calne DB. Positron emission tomographic evidence for progression of human MPTP-induced dopaminergic lesions. Ann Neurol. 1994;36:765-70.

17. Pezzoli G, Barbieri S, Ferrante C, Zecchinelli A, Foà V. Parkinsonism due to n-hexane exposure. Lancet. 1989;2:874.

18. Caparros-Lefebvre D, Elbaz A. Possible relation of atypical parkinsonism in the French West Indies with consumption of tropical plants: a case-control study. Caribbean Parkinsonism Study Group. Lancet. 1999;354:281-6.

19. Hernan MA, Takkouche B, Caamano-Isorna F, Gestal- Otero JJ. A meta-analysis of coffee drinking, cigarette smoking, and the risk of Parkinson's disease. Ann Neurol 2002;52:27684.

20. Parain K, Hapdey C, Rousselet E, Marchand V, Dumery B, Hirsch EC. Cigarette smoke and nicotine protect dopaminergic neurons against the 1-methyl-4-phenyl-1,2,3,6tetrahydropyridine Parkinsonian toxin. Brain Res. 2003;984:224-32. 
21. Gagne JJ, Power MC. Anti-inflammatory drugs and risk of Parkinson disease: a metaanalysis. Neurology 2010;74:995-1002.

22. Postuma RB, Poewe W, Litvan I, Lewis S, Lang AE, Halliday G, Goetz CG, Chan P, Slow E, Seppi K, Schaffer E, Rios-Romenets S, Mi T, Maetzler C, Li Y, Heim B, Bledsoe IO, Berg D. Validation of the MDS clinical diagnostic criteria for Parkinson's disease. Mov Disord. 2018;33:1601-1608.

23. Berg D, Adler CH, Bloem BR, Chan P, Gasser T, Goetz CG, Halliday G, Lang AE, Lewis S, Li Y, Liepelt-Scarfone I, Litvan I, Marek K, Maetzler C, Mi T, Obeso J, Oertel W, Olanow CW, Poewe W, Rios-Romenets S, Schäffer E, Seppi K, Heim B, Slow E, Stern M, Bledsoe IO, Deuschl G, Postuma RB. Movement disorder society criteria for clinically established early Parkinson's disease. Mov Disord. 2018;33:1643-1646.

24. Marek K, Seibyl J, Eberly S, et al. Longitudinal follow-up of SWEDD subjects in the PRECEPT Study. Parkinson Study Group PRECEPT Investigators. Neurology 2014;82:1791-1797.

25. Antonini A, Biundo R. Parkinson disease: Can dopamine transporter imaging define early PD? Nat Rev Neurol 2014;10:432-433.

26. Marras C, Rochon P, Lang AE. Predicting motor decline and disability in Parkinson disease: a systematic review. Arch Neurol. 2002;59:1724-8.

27. Post B, Merkus MP, de Haan RJ, Speelman JD; CARPA Study Group. Prognostic factors for the progression of Parkinson's disease: a systematic review. Mov Disord. 2007;22:183951.

28. Mestre TA, Eberly S, Tanner C, Grimes D, Lang AE, Oakes D, Marras C. Reproducibility of data-driven Parkinson's disease subtypes for clinical research. Parkinsonism Relat Disord. 2018;56:102-106.

29. Luz M, Whone A, Bassani N, Wyse R, Stebbins G, Mohr E. The Parkinson's Disease Comprehensive Response (PDCORE): a composite approach integrating three standard outcome measures. Brain Communications, fcaa046

30. de la Fuente-Fernández R1, Schulzer M, Kuramoto L, Cragg J, Ramachandiran N, Au WL, Mak E, McKenzie J, McCormick S, Sossi V, Ruth TJ, Lee CS, Calne DB, Stoessl AJ. Agespecific progression of nigrostriatal dysfunction in Parkinson's disease. Ann Neurol. 2011;69:803-10.

31. Fearnley JM, Lees AJ. Ageing and Parkinson's disease: substantia nigra regional selectivity. Brain. 1991;114:2283-301. 
32. Bernheimer H, Birkmayer W, Hornykiewicz O, Jellinger K, Seitelberger F. Brain dopamine and the syndromes of Parkinson and Huntington. Clinical, morphological and neurochemical correlations. J Neurol Sci. 1973;20:415-55.

33. Braak H, Del Tredici K, Rüb U, de Vos RA, Jansen Steur EN, Braak E. Staging of brain pathology related to sporadic Parkinson's disease. Neurobiol Aging. 2003;24:197-211.

34. Selikhova M, Williams DR, Kempster PA, Holton JL, Revesz T, Lees AJ.A clinicopathological study of subtypes in Parkinson's disease. Brain. 2009;132:2947-57.

35. Berg D, Postuma RB. From Prodromal to Overt Parkinson's Disease: Towards a New Definition in the Year 2040. J Parkinsons Dis. 2018;8:S19-S23.

36. Tolosa E, Vilas D. Peripheral synuclein tissue markers: a step closer to Parkinson's disease diagnosis. Brain 2015;138:2120-2.

37. Noyce AJ, Lees AJ1, Schrag AE. The prediagnostic phase of Parkinson's disease. J Neurol Neurosurg Psychiatry 2016;87:871-8.

38. Mollenhauer B, Caspell-Garcia CJ, Coffey CS, Taylor P, Singleton A, Shaw LM, Trojanowski JQ, Frasier M, Simuni T, Iranzo A, Oertel W, Siderowf A, Weintraub D, Seibyl J, Toga AW, Tanner CM, Kieburtz K, Chahine LM, Marek K, Galasko D; PPMI study. Longitudinal analyses of cerebrospinal fluid $\alpha$-Synuclein in prodromal and early Parkinson's disease. Mov Disord. 2019;34:1354-1364.

39. Kordower JH, Olanow CW, Dodiya HB, et al. Disease duration and the integrity of the nigrostriatal system in Parkinson's disease. Brain 2013;136:2419-2431.

40. Espay AJ, Brundin P, Lang AE. Precision medicine for disease modification in Parkinson disease. Nat Rev Neurol 2017;13:119- 126.

41. Braak H, Rub U, Gai WP, Del Tredici K. Idiopathic Parkinson's disease: possible routes by which vulnerable neuronal types may be subject to neuroinvasion by an unknown pathogen. J Neural Trans 2003;110:517-536.

42. Lang AE, Espay AJ. Disease Modification in Parkinson's Disease: Current Approaches, Challenges, and Future Considerations. Mov Disord. 2018;33:660-677.

43. Rascol O, "Disease-modification" trials in Parkinson disease: target populations, endpoints and study design. Neurology 2009; 72(7 Suppl):S51-S58.

44. Van der Schyf CJ., Rational drug discovery design approaches for treating Parkinson's disease, Expert Opin Drug Discov 2015;10: 713-741.

45. Thibault L, Rascol O, Corvol JC, Ferreira J, Defebvre L, Deplanque D, Bordet R, Moreau C, Devos D. New perspectives on study designs for evaluating neuroprotection in Parkinson's disease. Mov Disord. 2017;32:1365-1370. 
46. Arribarat G, Péran P. Quantitative MRI markers in Parkinson's disease and parkinsonian syndromes. Curr Opin Neurol. 2020;33:222-229.

47. Eckert T, Tang C, Eidelberg D. Assessment of the progression of Parkinson's disease: a metabolic network approach. Lancet Neurol. 2007;6:926-32.

48. Kalia LV, Lang AE, Hazrati LN, et al. Clinical correlations with Lewy body pathology in LRRK2-related Parkinson disease. JAMA Neurol 2015;72:100-105.

49. Parkkinen L, O’Sullivan SS, Collins C, et al. Disentangling the relationship between Lewy bodies and nigral neuronal loss in Parkinson's disease. J Parkinsons Dis 2011;1:277-286.

50. Patterson L, Rushton SP, Attems J, Thomas AJ, Morris CM. Degeneration of dopaminergic circuitry influences depressive symptoms in Lewy body disorders. Brain Pathol 2019;29:544-557.

51. Irwin DJ, Grossman M, Weintraub D, et al. Neuropathological and genetic correlates of survival and dementia onset in synucleinopathies: a retrospective analysis. Lancet Neurol 2017;16:55-65.

52. Buchman AS, Yu L, Wilson RS, et al. Progressive parkinsonism in older adults is related to the burden of mixed brain pathologies. Neurology 2019;92:e1821-e1830.

53. Visanji NP, Lang AE, Kovacs GG. Beyond the synucleinopathies: alpha synuclein as a driving force in neurodegenerative comorbidities. Translational neurodegeneration 2019;8:28.

54. Espay AJ, Vizcarra JA, Marsili L, et al. Revisiting protein aggregation as pathogenic in sporadic Parkinson and Alzheimer diseases. Neurology 2019;92:329-337.

55. Galluzzi L, Vitale I, Aaronson SA, Abrams JM, Adam D, Agostinis P, et al. Molecular mechanisms of cell death: recommendations of the nomenclature committee on cell death 2018. Cell Death Differ. 2018;25:486-541

56. Do Van B, Gouel F, Jonneaux A, Timmerman K, Gelé P, Pétrault M, Bastide M, Laloux C, Moreau C, Bordet R, Devos D, Devedjian JC. Ferroptosis, a newly characterized form of cell death in Parkinson's disease that is regulated by PKC. Neurobiol Dis. 2016;94:169-78.

57. Guiney S, Adlard P, Bush A, Finkelstein D, Ayton S. Ferroptosis and cell death mechanisms in Parkinson's disease. Neurochem Int. 2017;104:34-48.

58. Kam TI, Mao X, Park H, Chou SC, Karuppagounder SS, Umanah GE, Yun SP, Brahmachari S, Panicker N, Chen R, Andrabi SA, Qi C, Poirier GG, Pletnikova O, Troncoso JC, Bekris LM, Leverenz JB, Pantelyat A, Ko HS, Rosenthal LS, Dawson TM, Dawson VL. Poly(ADP-ribose) drives pathologic $\alpha$-synuclein neurodegeneration in Parkinson's disease. Science. 2018;362(6414):eaat8407. 
59. Cao J, Chen X, Jiang L, Lu B, Yuan M, Zhu D, Zhu H, He Q, Yang B, Ying M. DJ-1 suppresses ferroptosis through preserving the activity of S-adenosyl homocysteine hydrolase. Nat Commun. 2020;11:1251.

60. Wu Z, Geng Y, Lu X, Shi Y, Wu G, Zhang M, Shan B, Pan H, Yuan J. Chaperone-mediated autophagy is involved in the execution of ferroptosis. Proc Natl Acad Sci U S A. 2019;116:2996-3005.

61. Liu Y, Wang Y, Liu J, Kang R, Tang D. Interplay between MTOR and GPX4 signaling modulates autophagy-dependent ferroptotic cancer cell death. Cancer Gene Ther. 2020 May 27.

62. Höglinger G, Carrard G, Michel P, Medja F, Lombès A, Ruberg M, Friguet B, Hirsch E. Dysfunction of mitochondrial complex I and the proteasome: interactions between two biochemical deficits in a cellular model of Parkinson's disease. J Neurochem. 2003;86:1297-307.

\section{3. https://clinicaltrials.gov/ct2/show/NCT03127514}

64. Yacoubian T, Standaert D. Targets for neuroprotection in Parkinson's disease. Biochim Biophys Acta 2009;1792:676-87.

65. Slanzi A, Iannoto G, Rossi B, Zenaro E, Constantin G. In vitro Models of Neurodegenerative Diseases. Front Cell Dev Biol. 2020;8:328.

66. Cenci MA, Björklund A. Animal models for preclinical Parkinson's research: An update and critical appraisal. Prog Brain Res. 2020;252:27-59.

67. Carvey PM, Chang Q, Lipton JW, Ling Z. Prenatal exposure to the bacteriotoxin lipopolysaccharide leads to long-term losses of dopamine neurons in offspring: a potential, new model of Parkinson's disease. Front Biosci. 2003;8:s826-37.

68. Kolb B1, Teskey GC. Age, experience, injury, and the changing brain. Dev Psychobiol. 2012;54:311-25.

69. Adolfsson R, Gottfries CG, Roos BE, Winblad B. Post-mortem distribution of dopamine and homovanillic acid in human brain, variations related to age, and a review of the literature. J Neural Transm. 1979;45:81-105.

70. Loeffler DA, Connor JR, Juneau PL, et al. Transferrin and iron in normal, Alzheimer's disease, and Parkinson's disease brain regions. J Neurochem 1995;65:710-6.

71. Kairalla JA, Coffey CS, Thomann MA, Muller KE. Adaptive trial designs: a review of barriers and opportunities. Trials 2012;13:145. 
72. Park JH, Siden E, Zoratti MJ, Dron L, Harari O, Singer J, Lester RT, Thorlund K, Mills EJ. Systematic review of basket trials, umbrella trials, and platform trials: a landscape analysis of master protocols Trials. 2019;20:572.

73. Zeissler ML, Li V, Parmar MKB, Carroll CB. Is It Possible to Conduct a Multi-Arm MultiStage Platform Trial in Parkinson's Disease: Lessons Learned from Other Neurodegenerative Disorders and Cancer. J Parkinsons Dis. 2020;10:413-428.

74. Olanow CW., Hauser RA., Jankovic J., et al. A randomized, double-blind, placebocontrolled, delayed start study to assess rasa- giline as a disease modifying therapy in Parkinson's disease (the ADAGIO study): rationale, design. Mov Disord 2008;23:21942201.

75. Odin P, Chaudhuri KR, Volkmann J, Antonini A, Storch A, Dietrichs E, Pirtošek Z, Henriksen T, Horne M, Devos D, Bergquist F. Viewpoint and practical recommendations from a movement disorder specialist panel on objective measurement in the clinical management of Parkinson's disease. NPJ Parkinsons Dis. 2018;4:14.

76. Faucheux BA, Bonnet AM, Agid Y, Hirsch EC. Blood vessels change in the mesencephalon of patients with Parkinson's disease. Lancet. 1999;353:981-2.

77. Barcia C, Bautista V, Sánchez-Bahillo A, Fernández-Villalba E, Faucheux B, Poza y Poza M, Fernandez Barreiro A, Hirsch E C, Herrero M-T. Changes in vascularization in substantia nigra pars compacta of monkeys rendered parkinsonian. J Neural Transm (Vienna) 2005;112:1237-48.

78. Ohlin KE, Sebastianutto I, Adkins CE, Lundblad C, Lockman PR, Cenci MA. Impact of LDOPA treatment on regional cerebral blood flow and metabolism in the basal ganglia in a rat model of Parkinson's disease. Neuroimage. 2012;61:228-39.

79. Pires, P.C.; Santos, A.O. Nanosystems in nose-to-brain drug delivery: A review of nonclinical brain targeting studies. J. Control. Release 2017;270:89-100.

80. Dholkawala F, Voshavar C, Dutta AK. Synthesis and characterization of brain penetrant prodrug of neuroprotective D-264: Potential therapeutic application in the treatment of Parkinson's disease. Eur J Pharm Biopharm. 2016;103:62-70.

81. Georgieva, J.V.; Hoekstra, D.; Zuhorn, I.S. Smuggling drugs into the brain: An overview of ligands targeting transcytosis for drug delivery across the blood-brain barrier. Pharmaceutics 2014;6:557-583.

82. Gaudin A, Yemisci M, Eroglu H, Lepetre-Mouelhi S, Turkoglu OF, Dönmez-Demir B, Caban S, Sargon MF, Garcia-Argote S, Pieters G, Loreau O, Rousseau B, Tagit O, Hildebrandt N, Le Dantec Y, Mougin J, Valetti S, Chacun H, Nicolas V, Desmaële D, 
Andrieux K, Capan Y, Dalkara T, Couvreur P. Squalenoyl adenosine nanoparticles provide neuroprotection after stroke and spinal cord injury. Nat Nanotechnol. 2014;9:1054-1062.

83. Mursaleen L, Noble B, Stefanie Ho Y Chan S, Somavarapu S and Zariwala1 M. NAcetylcysteine Nanocarriers Protect against Oxidative Stress in a Cellular Model of Parkinson's Disease. Antioxidants (Basel). 2020;9: 600.

84. He Q, Liu J, Liang J, Liu X, Li W, Liu Z, Ding Z, Tuo D. Towards Improvements for Penetrating the Blood-Brain Barrier-Recent Progress from a Material and Pharmaceutical Perspective. Cells. 2018;7.pii: E24.

85. Hasnat MJ1, Rice JE. Intrathecal baclofen for treating spasticity in children with cerebral palsy. Cochrane Database Syst Rev. 2015;11:CD004552.

86. Paul G, Zachrisson O, Varrone A, Almqvist P, Jerling M, Lind G, Rehncrona S, Linderoth B, Bjartmarz H, Shafer LL, Coffey R, Svensson M, Mercer KJ, Forsberg A, Halldin C, Svenningsson P, Widner H, Frisén J, Pålhagen S, Haegerstrand A. Safety and tolerability of intracerebroventricular PDGF-BB in Parkinson's disease patients. J Clin Invest. 2015;125:1339-46

87. Burgess A, Shah K, Hough O, Hynynen K. Focused ultrasound-mediated drug delivery through the blood-brain barrier. Expert Rev Neurother. 2015;15:477-91.

88. Le Floc'h J, Lu HD, Lim TL, Démoré C, Prud'homme RK, Hynynen K, Foster FS. Transcranial Photoacoustic Detection of Blood-Brain Barrier Disruption Following Focused Ultrasound-Mediated Nanoparticle Delivery. Mol Imaging Biol. 2020;22:324-334

89. Dickson M, Gagnon JP. Key factors in the rising cost of new drug discovery and development. Nat Rev Drug Discov. 2004;3:417-29.

90. Devos D, Moreau C, Devedjian JC, Kluza J, Petrault M, Laloux C, Jonneaux A, Ryckewaert G, Garçon G, Rouaix N, Duhamel A, Jissendi P, Dujardin K, Auger F, Ravasi L, Hopes L, Grolez G, Firdaus W, Sablonnière B, Strubi-Vuillaume I, Zahr N, Destée A, Corvol JC, Pöltl D, Leist M, Rose C, Defebvre L, Marchetti P, Cabantchik ZI, Bordet R. Targeting chelatable iron as a therapeutic modality in Parkinson's disease. Antioxid Redox Signal. 2014;21:195-210.

91. Moreau C, Duce JA, Rascol O, Devedjian JC, Berg D, Dexter D, Cabantchik ZI, Bush AI, Devos D; FAIRPARK-II study group. Iron as a therapeutic target for Parkinson's disease. Mov Disord. 2018;33:568-574. www.fairpark2.eu

92. McFarthing K, Buff S, Rafaloff. G, Dominey T, Wyse R, Stott S. Parkinson's disease drug therapies in the clinical trial pipeline: 2020. J Parkinsons Dis. 2020;10:757-774. 


\section{Legends}

Figure 1: Past and current therapeutic strategies illustrating the need of biomarkers of target engagements

Main physiopathological mechanisms (orange boxes) with complex and multiple interplays (arrows to show that they are in fact all connected), failed past therapeutic strategies (light blue boxes), strategies currently in clinical trials (dark blue boxes). (sources: ${ }^{42,92}$ and www.clinicaltrials.gov). None of the past and failed trials matched the therapies tested with the suitable molecular biology of the intended recipients. Thus, there is an urgent need of biomarkers that can demonstrate the molecular susceptibility to the mechanism of the drugs in order to validate target engagement and to assess drug response in patients.

Figure 2: Vocabulary of treatment modalities according to (a) the impact on the neuronal count in preclinical models and (b) on the clinical handicap progression in patients.

\section{Figure 3: Seven solutions}

Organization of seven interconnected solutions of varying importance that can be exclusive or additive and outline approaches to help generate successful development of efficient treatments aiming at reducing the rate of downward trajectory of disease progression.

Abbreviations: PD: Parkinson's disease 


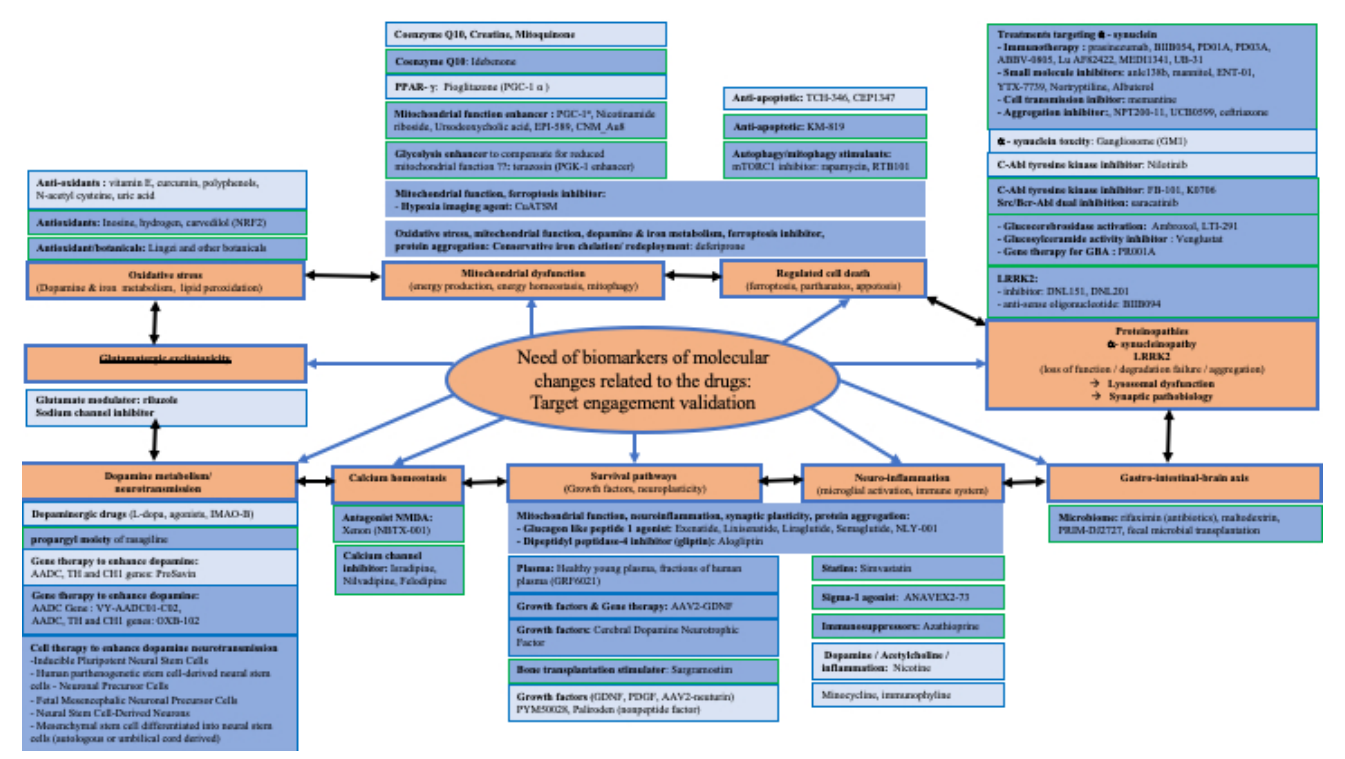

Figure 1

$338 \times 190 \mathrm{~mm}$ ( 54 x 54 DPI) 

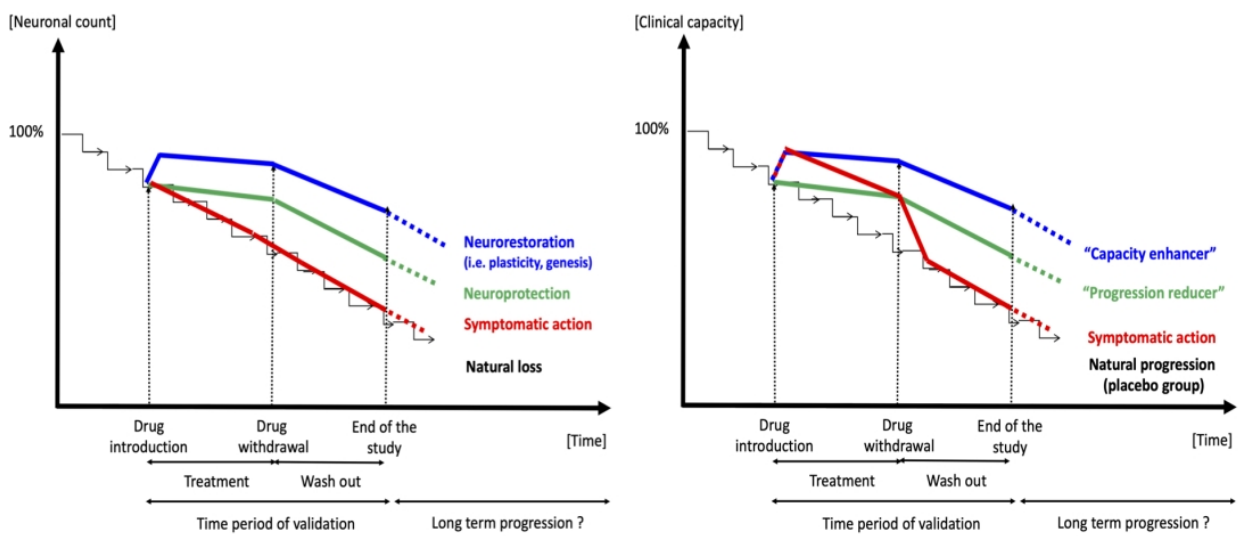

Figure 2

$338 \times 190 \mathrm{~mm}(150 \times 150$ DPI $)$

John Wiley \& Sons 
Figure 3

254x190mm (72 x 72 DPI)

Solution 6

To reduce the risk of drug development ustomize drugs with better and more selective brain accessibility

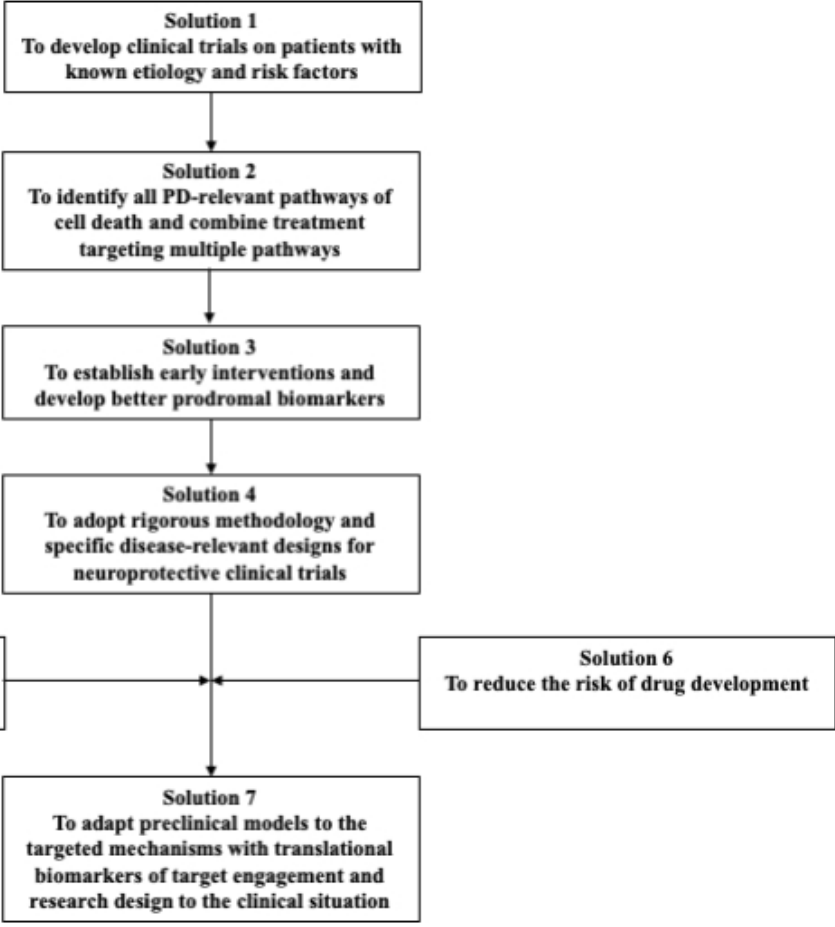

